\title{
A semi-analytical elastic stress solution for circular rock stratum based on the theory of curved beam
}

wankui BU

Heze University

Hui XU ( $\nabla$ xu_hui521@126.com )

Heze University

\section{Research}

Keywords: elastic stress solution, circular rock stratum, elastic mechanics, displacement function, curved beam

Posted Date: September 17th, 2021

DOI: https://doi.org/10.21203/rs.3.rs-880094/v1

License: (c) (1) This work is licensed under a Creative Commons Attribution 4.0 International License. Read Full License 


\title{
A semi-analytical elastic stress solution for circular rock stratum
}

\section{based on the theory of curved beam}

\author{
Wankui BU, Hui XU* \\ Heze University, Heze 274015, China
}

\begin{abstract}
The circular rock stratum are inevitably encountered in underground mining engineering, which causes waste of resources and dynamic instability. Based on the elastic theory of curved beam and finite-difference computation, a displacement function is presented in polar coordinates for solving two partial differential equations with the boundary conditions in mixed type in elastic, isotropic and homogeneous rock. A semi-analytical elastic stress solution for circular rock stratum is obtained according to the governing equation and stress components in terms of displacement function. The variations of stress distribution with different influencing factors are analyzed, which may lead to a better understanding of the stability of circular rock stratum after coal extractions. Finally, this semi-analytical elastic stress solution is applied to the fold structure in No.2502 mining area and points out the dangerous sites during coal extractions, which provides the basis of construction and safety in coal mine engineering.
\end{abstract}

Keywords: elastic stress solution; circular rock stratum; elastic mechanics; displacement function; curved beam

\section{Introduction}

Coal resources have always been and will been the main energy for a long time in China, which account for about $70 \%$ in the disposable energy structure. (Hu et al 2008, $\mathrm{He}$ et al 2010). However, a considerable proportion of coal resources exist in the series of continuous circular rock stratum and are threatened by dynamic instability during coal mining. A feature common to circular rock stratum is that there are the curvature and horizontal tectonic stress in the rock formations, which lead to deforms elastically at the very least during the coal extractions. An understanding of the distribution of elastic stress for circular rock stratum after coal extractions is quite important for underground mining engineering, which is different from the stress distribution for horizontal layered stratum. Although the visualizing stress solutions for circular rock stratum can be obtained by the use of numerical modeling, the analytical solution for circular rock stratum provide the insight into the general nature of the solution. On the other hand, the mining engineers should be able to assess the general correctness of a numerical analysis because of the simplification of numerical modeling, however, the analytical solution provide a valuable means of making this assessment. Therefore, the elastic stress distribution for circular rock stratum may become a significant research for mining engineers.

Classically, stress function formula and displacement function formula are the two common methods for stress analysis of curved beams in elastic mechanics. For the former, it is the simplest method for curved beam in elastic mechanics, and many researchers (Timoshenko et al. 1979, Oden et al. 1981, Chianese et al. 1988, Bagci 1992, Bagci 1993, Cook 1992, Tutuncu 1998, Sloboda et al. 2007, etc.) obtain the stress solutions with improved calculation methods for curved beam with different cross sections or different loading. However, it cannot get satisfied solution when the 
boundary conditions are in form of displacement conditions or strain conditions. For the latter, it is not widely applied to geotechnical engineering because there is a difficulty in solving two partial differential equations for radial displacement and circumferential displacement. Especially, it is impossible to get exact solutions from two partial differential equations with variable coefficients when the boundary conditions are in mixed mode of displacement (strain) and loading (stress). Therefore, it seems that these traditional methods are inaccurate and unreliable for these problems with mixed boundary-value type (Durelli et al. 1989, Ahmed et al. 1996, Ahmed et al. 1998). On the other hand, some researchers, such as W.X. Zhong, etc, introduced the Hamiltonian system into the elastic problems and established Symplectic Elasticity, which has the defect of breaking off in Jordan chain (Zhong et al. 1996).

In recent years, some literatures have been reported on the solution for boundary conditions in mixed type by combining the elastic mechanics and computational mechanics. The common methods for numerical calculation are the finite element method (FEM) and the finite difference method (FDM). The FEM has been successfully and widely applied in stress analysis (Cook 1989, Rattanawangcharoen 2004, Richards et al. 1987, Smart 1987), however, some researchers point out that there is a defect of calculation results for large bending deformation in FEM (Gangan 1985). Furthermore, it has been proved that the calculation results in FDM is better than that in FEM (Dow et al. 1990, Ranzi et al. 2006, Ahmed et al. 2005).

Based on the above consideration, a displacement function is presented in polar coordinates for solving two partial differential equations with the boundary conditions in mixed type in elastic, isotropic and homogeneous rock. Subsequently, the radial displacement and circumferential displacement are expressed as a summation of all possible partial derivatives of the displacement function up to an order of two with unknown coefficients. The displacement function and its numerical solutions are obtained by a finite-difference computation. Meanwhile, the variations of stress distribution with different influencing factors are analyzed according to the analytical expression of stress components in terms of displacement function. Finally, this semianalytical elastic stress solution is applied to the fold structure in No.2502 mining area in China.

\section{Elastic stress solution for circular rock stratum}

\subsection{Governing equation in terms of displacement function}

According to elastic mechanics in polar coordinates system $(r, \theta)$ (Oden 1981, Timoshenko 1979), the equilibrium equations in form of radial displacement $u_{r}$ and circumferential displacement $u_{\theta}$ in plane problem without body force are as follows:

$$
\begin{gathered}
\frac{\partial^{2} u_{r}}{\partial r^{2}}+\frac{1}{2 r(1-\mu)} \frac{\partial^{2} u_{\theta}}{\partial r \partial \theta}+\frac{(1-2 \mu)}{2 r^{2}(1-\mu)} \frac{\partial^{2} u_{r}}{\partial \theta^{2}}+\frac{1}{r} \frac{\partial u_{r}}{\partial r}-\frac{(3-4 \mu)}{2 r^{2}(1-\mu)} \frac{\partial u_{\theta}}{\partial \theta}-\frac{u_{r}}{r^{2}}=0 \\
\frac{(1-2 \mu)}{2(1-\mu)} \frac{\partial^{2} u_{\theta}}{\partial r^{2}}+\frac{1}{2 r(1-\mu)} \frac{\partial^{2} u_{r}}{\partial r \partial \theta}+\frac{1}{r^{2}} \frac{\partial^{2} u_{\theta}}{\partial \theta^{2}}+\frac{(1-2 \mu)}{2 r(1-\mu)} \frac{\partial u_{\theta}}{\partial r}+\frac{(3-4 \mu)}{2 r^{2}(1-\mu)} \frac{\partial u_{r}}{\partial \theta}-\frac{(1-2 \mu)}{2 r^{2}(1-\mu)} u_{\theta}=0
\end{gathered}
$$

Where, $u_{\theta}$ and $u_{r}$ are the circumferential displacement and radial displacement, respectively. $\mu$ is the Poisson's ration.

Eqs.(1) gives two partial differential equations for plane strain conditions in polar 
coordinate system. The exact solution of the radial displacement and circumferential displacement is that satisfying these two equations and boundary conditions. However, these two equations are the simultaneous partial differential equations with variable coefficients. Moreover, the boundary conditions are in mixed type of displacement (strain) and loading (stress) Thus, the exact results in this case is impossible. The mathematical method can be adopted that reducing the variables. The feasible option is that changing two equations with two variables into one equation with single variable.

In order to reduce the two variables with two governing equations in Eqs.(1) to one equation with single variable, a displacement function $\psi(r, \theta)$ is introduced, and the radial displacement and circumferential displacement are expressed as follows:

$$
\begin{aligned}
& u_{r}=\alpha_{1} \frac{\partial^{2} \psi}{\partial r^{2}}+\alpha_{2} \frac{1}{r} \frac{\partial^{2} \psi}{\partial r \partial \theta}+\alpha_{3} \frac{1}{r^{2}} \frac{\partial^{2} \psi}{\partial \theta^{2}}+\alpha_{4} \frac{1}{r} \frac{\partial \psi}{\partial r}+\alpha_{5} \frac{1}{r^{2}} \frac{\partial \psi}{\partial \theta}+\alpha_{6} \frac{1}{r^{2}} \psi \\
& u_{\theta}=\alpha_{7} \frac{\partial^{2} \psi}{\partial r^{2}}+\alpha_{8} \frac{1}{r} \frac{\partial^{2} \psi}{\partial r \partial \theta}+\alpha_{9} \frac{1}{r^{2}} \frac{\partial^{2} \psi}{\partial \theta^{2}}+\alpha_{10} \frac{1}{r} \frac{\partial \psi}{\partial r}+\alpha_{11} \frac{1}{r^{2}} \frac{\partial \psi}{\partial \theta}+\alpha_{12} \frac{1}{r^{2}} \psi
\end{aligned}
$$

Where, the coefficients $\alpha_{i}(i=1,2,3, \ldots, 12)$ are defined as material constants (Ahmed 2005).

Substituting the above expressions of $u_{r}$ and $u_{\theta}$ into Eqs. (1), the two partial differential equations in form of displacement function are given as follows:

$$
\begin{aligned}
& \alpha_{1} \frac{\partial^{4} \psi}{\partial r^{4}}+\frac{1}{r}\left\{\alpha_{2}+\frac{1}{2(1-\mu)} \alpha_{7}\right\} \frac{\partial^{4} \psi}{\partial r^{3} \partial \theta}+\frac{1}{r^{2}}\left\{\frac{1-2 \mu}{2(1-\mu)} \alpha_{1}+\alpha_{3}+\frac{1}{2(1-\mu)} \alpha_{8}\right\} \frac{\partial^{4} \psi}{\partial r^{2} \partial \theta^{2}} \\
& +\frac{1}{r^{3}}\left\{\frac{1-2 \mu}{2(1-\mu)} \alpha_{2}+\frac{1}{2(1-\mu)} \alpha_{9}\right\} \frac{\partial^{4} \psi}{\partial r \partial \theta^{3}}+\frac{1}{r^{4}}\left\{\frac{1-2 \mu}{2(1-\mu)} \alpha_{3}\right\} \frac{\partial^{4} \psi}{\partial \theta^{4}}+\frac{1}{r}\left\{\alpha_{1}+\alpha_{4}\right\} \frac{\partial^{3} \psi}{\partial r^{3}} \\
& +\frac{1}{r^{2}}\left\{-\alpha_{2}+\alpha_{5}-\frac{3-4 \mu}{2(1-\mu)} \alpha_{7}+\frac{1}{2(1-\mu)} \alpha_{10}\right\} \frac{\partial^{3} \psi}{\partial r^{2} \partial \theta} \\
& +\frac{1}{r^{3}}\left\{-3 \alpha_{3}+\frac{1-2 \mu}{2(1-\mu)} \alpha_{4}-2 \alpha_{8}+\frac{1}{2(1-\mu)} \alpha_{11}\right\} \frac{\partial^{3} \psi}{\partial r \partial \theta^{2}} \\
& +\frac{1}{r^{4}}\left\{\frac{1-2 \mu}{2(1-\mu)} \alpha_{5}+\frac{-5+4 \mu}{2(1-\mu)} \alpha_{9}\right\} \frac{\partial^{3} \psi}{\partial \theta^{3}}+\frac{1}{r^{2}}\left\{-\alpha_{1}-\alpha_{4}+\alpha_{6}\right\} \frac{\partial^{2} \psi}{\partial r^{2}} \\
& +\frac{1}{r^{3}}\left\{-3 \alpha_{5}-2 \alpha_{10}+\frac{1}{2(1-\mu)} \alpha_{12}\right\} \frac{\partial^{2} \psi}{\partial r \partial \theta}+\frac{1}{r^{4}}\left\{3 \alpha_{3}+\frac{1-2 \mu}{2(1-\mu)} \alpha_{6}-\frac{5-4 \mu}{2(1-\mu)} \alpha_{11}\right\} \frac{\partial^{2} \psi}{\partial \theta^{2}} \\
& +\frac{1}{r^{3}}\left\{-3 \alpha_{6}\right\} \frac{\partial \psi}{\partial r}+\frac{1}{r^{4}}\left\{3 \alpha_{5}-\frac{5-4 \mu}{2(1-\mu)} \alpha_{12}\right\} \frac{\partial \psi}{\partial \theta}+\frac{1}{r^{4}}\left\{3 \alpha_{6}\right\} \psi=0
\end{aligned}
$$




$$
\begin{aligned}
& \frac{1-2 \mu}{2(1-\mu)} \alpha_{7} \frac{\partial^{4} \psi}{\partial r^{4}}+\frac{1}{r}\left\{\frac{1}{2(1-\mu)} \alpha_{1}+\frac{1-2 \mu}{2(1-\mu)} \alpha_{8}\right\} \frac{\partial^{4} \psi}{\partial r^{3} \partial \theta} \\
& +\frac{1}{r^{2}}\left\{\frac{1}{2(1-\mu)} \alpha_{2}+\alpha_{7}+\frac{1-2 \mu}{2(1-\mu)} \alpha_{9}\right\} \frac{\partial^{4} \psi}{\partial r^{2} \partial \theta^{2}}+\frac{1}{r^{3}}\left\{\frac{1}{2(1-\mu)} \alpha_{3}+\alpha_{8}\right\} \frac{\partial^{4} \psi}{\partial r \partial \theta^{3}} \\
& +\frac{1}{r^{4}}\left\{\alpha_{9}\right\} \frac{\partial^{4} \psi}{\partial \theta^{4}}+\frac{1}{r}\left\{\frac{1-2 \mu}{2(1-\mu)} \alpha_{7}+\frac{1-2 \mu}{2(1-\mu)} \alpha_{10}\right\} \frac{\partial^{3} \psi}{\partial r^{3}} \\
& +\frac{1}{r^{2}}\left\{\frac{3-4 \mu}{2(1-\mu)} \alpha_{1}+\frac{1}{2(1-\mu)} \alpha_{4}-\frac{1-2 \mu}{2(1-\mu)} \alpha_{8}+\frac{1-2 \mu}{2(1-\mu)} \alpha_{11}\right\} \frac{\partial^{3} \psi}{\partial r^{2} \partial \theta} \\
& +\frac{1}{r^{3}}\left\{\frac{1-2 \mu}{1-\mu} \alpha_{2}+\frac{1}{2(1-\mu)} \alpha_{5}-\frac{3(1-2 \mu)}{2(1-\mu)} \alpha_{9}+\alpha_{10}\right\} \frac{\partial^{3} \psi}{\partial r \partial \theta^{2}} \\
& +\frac{1}{r^{4}}\left\{\frac{1-4 \mu}{2(1-\mu)} \alpha_{3}+\alpha_{11}\right\} \frac{\partial^{3} \psi}{\partial \theta^{3}}+\frac{1}{r^{2}}\left\{-\frac{1-2 \mu}{2(1-\mu)} \alpha_{7}-\frac{1-2 \mu}{2(1-\mu)} \alpha_{10}+\frac{1-2 \mu}{2(1-\mu)} \alpha_{12}\right\} \frac{\partial^{2} \psi}{\partial r^{2}} \\
& +\frac{1}{r^{3}}\left\{\frac{1-2 \mu}{1-\mu} \alpha_{4}+\frac{1}{2(1-\mu)} \alpha_{6}-\frac{3(1-2 \mu)}{2(1-\mu)} \alpha_{11}\right\} \frac{\partial^{2} \psi}{\partial r \partial \theta} \\
& +\frac{1}{r^{4}}\left\{\frac{1-4 \mu}{2(1-\mu)} \alpha_{5}+\frac{3(1-2 \mu)}{2(1-\mu)} \alpha_{9}+\alpha_{12}\right\} \frac{\partial^{2} \psi}{\partial \theta^{2}}+\frac{1}{r^{3}}\left\{-\frac{3(1-2 \mu)}{2(1-\mu)} \alpha_{12}\right\} \frac{\partial \psi}{\partial r} \\
& +\frac{1}{r^{4}}\left\{\frac{1-4 \mu}{2(1-\mu)} \alpha_{6}+\frac{3(1-2 \mu)}{2(1-\mu)} \alpha_{11}\right\} \frac{\partial \psi}{\partial \theta}+\frac{1}{r^{4}}\left\{\frac{3(1-2 \mu)}{2(1-\mu)} \alpha_{12}\right\} \psi=0
\end{aligned}
$$

In this case, one of Eqs. (3) should be vanished reasonably for getting the solution of variable $\psi(r, \theta)$. In mathematical method, one of Eqs. (3) should satisfy with all conditions. Fortunately, when the coefficients of all partial derivatives of variable $\psi(r, \theta)$ and the coefficient of variable $\psi(r, \theta)$ in one of Eqs.(3) are all zero, this equation will be vanished.

In this case, the coefficients in Eq. (3a) are all zero and the Eq. (3b) is the only one equation for solving displacement function $\psi(r, \theta)$, which is called governing equation. Here, we make the coefficients of all partial derivatives of variable $\psi(r, \theta)$ and the coefficient of variable $\psi(r, \theta)$ in Eq.(3a) equate to zero. The values of constants $\alpha_{i}$ can be obtained and substituted into Eq. (3b). The explicit expression of the equation in form of variable $\psi(r, \theta)$ is as follows.

$$
\frac{\partial^{4} \psi}{\partial r^{4}}+\frac{1}{r^{4}} \frac{\partial^{4} \psi}{\partial \theta^{4}}+\frac{2}{r^{2}} \frac{\partial^{4} \psi}{\partial r^{2} \partial \theta^{2}}-\frac{2}{r} \frac{\partial^{3} \psi}{\partial r^{3}}-\frac{6}{r^{3}} \frac{\partial^{3} \psi}{\partial r \partial \theta^{2}}+\frac{5}{r^{2}} \frac{\partial^{2} \psi}{\partial r^{2}}+\frac{10}{r^{4}} \frac{\partial^{2} \psi}{\partial \theta^{2}}-\frac{9}{r^{3}} \frac{\partial \psi}{\partial r}+\frac{9}{r^{4}} \psi=0
$$

Eq.(4) gives the expression of governing equation for plane strain problems in polar coordinates. On other hand, if the Eq.(3b) satisfy with all conditions, the Eq. (3a) will be the only equation in form of variable $\psi(r, \theta)$. The explicit expression of the equation in form of variable function $\psi(r, \theta)$ is also obtained by the same way, which is the same as that of Eq.(4). Thus, the conclusion is that equation for plane problems in polar coordinates is unique.

\subsection{Physical components expressed by displacement function}

In order to solve Eq. (4), the boundary condition should be known at any point with all boundary. As all know, the boundary condition of displacements and stress are usually known. Thus, it is necessary to describe physical components in form of variable $\psi(r, \theta)$. There are two displacement components including radial displacement $u_{r}$ and circumferential displacement $u_{\theta}$, and there are three stress components including radial stress $\sigma_{r}$, circumferential stress $\sigma_{\theta}$ and shear stress $\tau_{r \theta}$.

Displacement components expressed by displacement function: 


$$
\begin{aligned}
& u_{r}=-\frac{1}{2 r(1-\mu)} \frac{\partial^{2} \psi}{\partial r \partial \theta}+\frac{(5-4 \mu)}{2 r^{2}(1-\mu)} \frac{\partial \psi}{\partial \theta} \\
& u_{\theta}=\frac{\partial^{2} \psi}{\partial r^{2}}+\frac{(1-2 \mu)}{2 r^{2}(1-\mu)} \frac{\partial^{2} \psi}{\partial \theta^{2}}-\frac{3}{r} \frac{\partial \psi}{\partial r}+\frac{3}{r^{2}} \psi
\end{aligned}
$$

Stress components expressed by displacement function:

$$
\begin{gathered}
\sigma_{r}=\frac{E}{2(1+\mu)}\left[-\frac{1}{r} \frac{\partial^{3} \psi}{\partial r^{2} \partial \theta}+\frac{\mu}{r^{3}(1-\mu)} \frac{\partial^{3} \psi}{\partial \theta^{3}}+\frac{(6-5 \mu)}{r^{2}(1-\mu)} \frac{\partial^{2} \psi}{\partial r \partial \theta}-\frac{(10-9 \mu)}{r^{3}(1-\mu)} \frac{\partial \psi}{\partial \theta}\right] \\
\sigma_{\theta}=\frac{E}{2(1+\mu)}\left[\frac{(2-\mu)}{r(1-\mu)} \frac{\partial^{3} \psi}{\partial r^{2} \partial \theta}+\frac{1}{r^{3}} \frac{\partial^{3} \psi}{\partial \theta^{3}}-\frac{(7-5 \mu)}{r^{2}(1-\mu)} \frac{\partial^{2} \psi}{\partial r \partial \theta}+\frac{(11-9 \mu)}{r^{3}(1-\mu)} \frac{\partial \psi}{\partial \theta}\right] \\
\tau_{r \theta}=\frac{E}{2(1+\mu)}\left[\frac{\partial^{3} \psi}{\partial r^{3}}-\frac{\mu}{r^{2}(1-\mu)} \frac{\partial^{3} \psi}{\partial r \partial \theta^{2}}-\frac{4}{r} \frac{\partial^{2} \psi}{\partial r^{2}}+\frac{1+\mu}{r^{3}(1-\mu)} \frac{\partial^{2} \psi}{\partial \theta^{2}}+\frac{9}{r^{2}} \frac{\partial \psi}{\partial r}-\frac{9}{r^{3}} \psi\right]
\end{gathered}
$$

\section{Numerical Analysis of Stress for Circular Rock Stratum}

\subsection{Object for Investigating}

The schematic diagram of coal extractions in circular rock strata is shown in Fig.1 according to the feature of the curvature and horizontal tectonic stress in the rock formations. The shape of rock strata is simplified as a circular arc with a radius for the feasibility of theoretical analysis. After coal extractions, the confining stress reduces to zero on the boundary of the goaf and the stress is redistributed for the overburden rock strata and floor rock strata. From a deformation point of view the overburden rock strata above the goaf are falling down and the floor rock strata are heaving up, which will lead to instability deformation and affect the mining production. The object for investigating is the red region in Fig.1, which is the first stratum above the goaf.

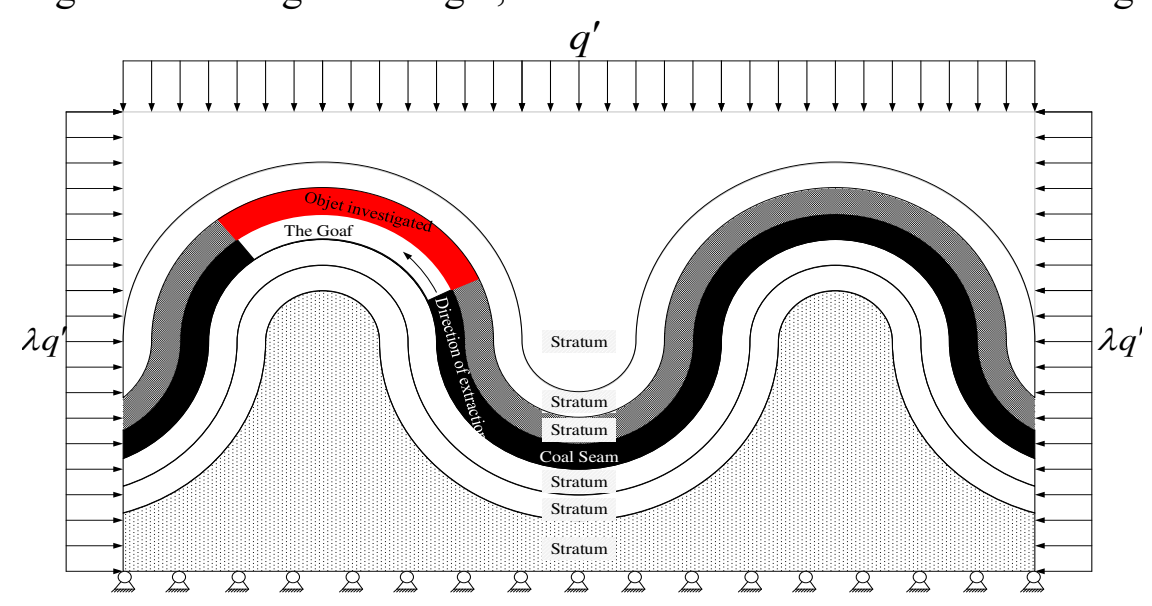

Fig.1 Schematic diagram of coal extractions in circular rock strata

\subsection{Numerical Model for Computation}

The numerical model for computation in circular rock stratum with plane strain problem is given in Fig.2, where $r_{i b}$ and $r_{o b}$ are the inner radius and outer radius, respectively.

The boundary conditions in left and right boundary are the displacement restrain with roller support. The boundary conditions in outer surface is the stress restrain because of horizontal stress $\lambda q$ and vertical stress $q$ in rock strata (the parameter $\lambda$ is the 
tectonic stress coefficient) while the stress in inner surface is zero because of coal extractions. The angle $\theta_{i}$ between horizontal line and open-off cut is named mining position and the angle $\theta_{e}$ between working face and open-off cut is named advancing angle. The thickness of circular rock stratum is symbolized as st.

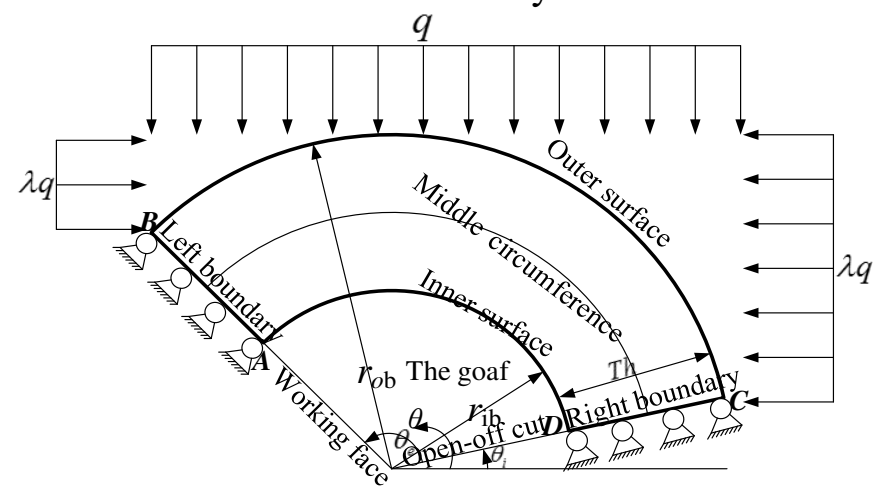

Fig.2 Numerical model for computation in circular rock stratum

In this paper, the finite difference method is employed and there are many finite discrete points in computation domain for obtaining the value of displacement function $\psi(r, \theta)$. Therefore, the discrete points in computation domain should satisfy the governing equation Eq.4 and the discrete points in boundary should satisfy the boundary conditions in Fig.2. Table 1 lists the values of stress or displacement in the boundary and Table 2 lists specially the value of stress or displacement at the four corner points in numerical model. It is obvious that two values of displacement and one value of stress are must satisfied at the four corner points, which is superior to the traditional computing methods with only two values of stress or displacement being satisfied. Therefore, the stress solution around the corner regions with the method in this paper will be close to the actual state while the stress solution with traditional method will deviate the actual state. The mesh length in radial direction and circumferential direction is $0.5 \mathrm{~m}$ and $1^{\circ}$ respectively.

Table 1 The value of stress or displacement in the boundary in numerical model

\begin{tabular}{ccc}
\hline Boundary & \multicolumn{2}{c}{ Boundary conditions } \\
\cline { 2 - 3 } Right $\theta=\theta_{i}$ & $u_{r}\left(r, \theta_{i}\right)=0$ & Tangential component \\
\hline Left $\theta=\theta_{\text {max }}=\theta_{i}+\theta_{e}$ & $u_{r}\left(r, \theta_{\text {max }}\right)=0$ & $u_{\theta}\left(r, \theta_{i}\right)=0$ \\
Inner surface $r=r_{i b}$ & $\sigma_{r}\left(r_{i b}, \theta\right)=0$ & $u_{\theta}\left(r, \theta_{\text {max }}\right)=0$ \\
& & $\tau_{r \theta}\left(r_{i b}, \theta\right)=0$
\end{tabular}

Outer surface

$r=r_{o b}, \theta \leq 90^{\circ}$

$\sigma_{r}\left(r_{o b}, \theta\right)=-q(\lambda \cos \theta+\sin \theta) \quad \tau_{r \theta}\left(r_{o b}, \theta\right)=-q(\cos \theta-\lambda \sin \theta)$ 
Outer surface

$r=r_{o b}, \theta>90^{\circ}$

$$
\sigma_{r}\left(r_{o b}, \theta\right)=-q(-\lambda \cos \theta+\sin \theta) \quad \tau_{r \theta}\left(r_{o b}, \theta\right)=-q(\cos \theta+\lambda \sin \theta)
$$

Table 2 The value of stress or displacement at the four corner points in numerical model

\begin{tabular}{ccc}
\hline Corner point & Boundary conditions & $\begin{array}{c}\text { The value of stress or } \\
\text { displacement }\end{array}$ \\
\hline$A$ & $\left\{u_{r}, u_{\theta}, \sigma_{r}, \tau_{r \theta}\right\}$ & $u_{r}=0 ; u_{\theta}=0 ; \tau_{r \theta}=0$ \\
$B$ & $\left\{u_{r}, u_{\theta}, \sigma_{r}, \tau_{r \theta}\right\}$ & $u_{r}=0 ; u_{\theta}=0 ; \tau_{r \theta}=0$ \\
$C$ & $\left\{u_{r}, u_{\theta}, \sigma_{r}, \tau_{r \theta}\right\}$ & $u_{r}=0 ; u_{\theta}=0 ; \tau_{r \theta}=0$ \\
$D$ & $\left\{u_{r}, u_{\theta}, \sigma_{r}, \tau_{r \theta}\right\}$ & $u_{r}=0 ; u_{\theta}=0 ; \tau_{r \theta}=0$
\end{tabular}

\subsection{The stress distribution for circular rock stratum}

\subsubsection{The factor of inner radius}

Given that the tectonic stress coefficient $\lambda$ is 1.8 , the mining depth $m d$ is $1000 \mathrm{~m}$, the mining position $\theta_{i}$ is $0^{\circ}$, the advancing angle $\theta_{e}$ is $120^{\circ}$, the thickness of circular rock stratum $s t$ is $20 \mathrm{~m}$ and the inner radius $r_{i b}$ is assigned $5 \mathrm{~m}, 10 \mathrm{~m}, 20 \mathrm{~m}, 40 \mathrm{~m}, 50 \mathrm{~m}$, $60 \mathrm{~m}, 80 \mathrm{~m}$ and $100 \mathrm{~m}$, respectively. The stress components along middle circumference with different inner radii are analyzed as follows.

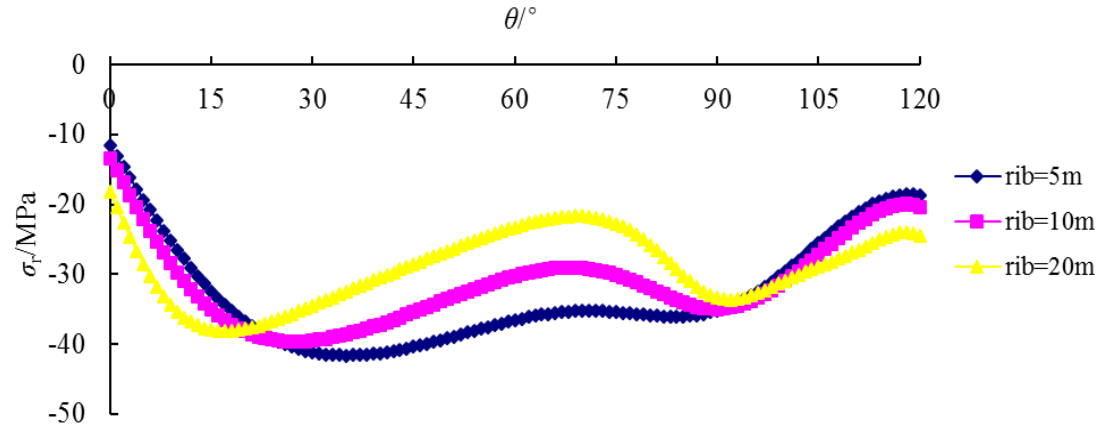

(a)

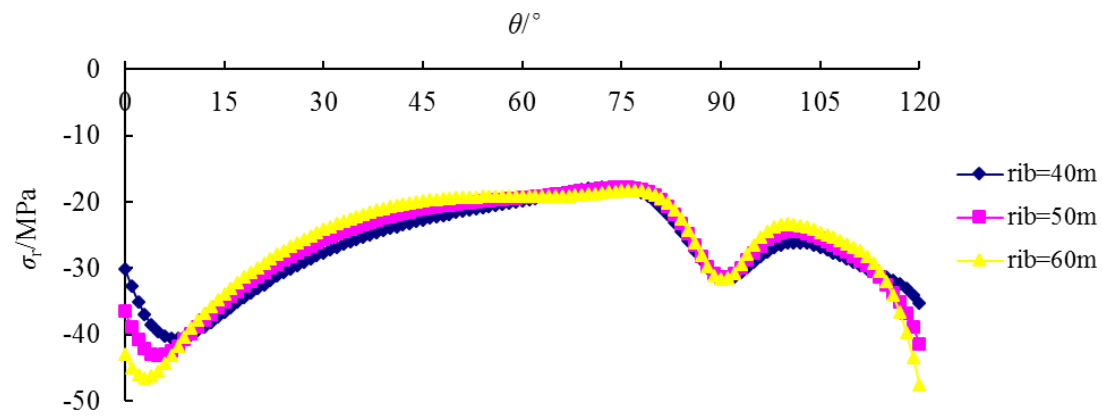

(b) 


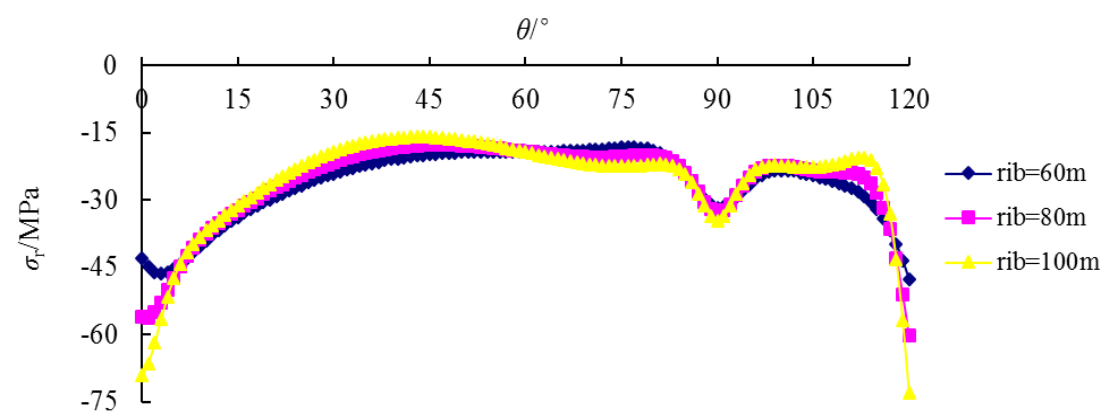

(c)

Fig.3 The radial stress distribution along middle circumference with different inner radii

Fig. 3 gives the radial stress distribution along middle circumference with different inner radii. We can reach a conclusion that the radial stress on left and right boundary increase gradually with the increasing of inner radius. Giving an example, the radial stress on left and right boundary increases from $18.65 \mathrm{MPa}, 11.60 \mathrm{MPa}$ to $73.05 \mathrm{MPa}$, 69.08MPa when inner radius increases from $5 \mathrm{~m}$ to $100 \mathrm{~m}$. The radial stress increases nearly 3 to 5 times for left and right boundary when the inner radius increases 19 times from $5 \mathrm{~m}$ to $100 \mathrm{~m}$. It can be obtained that the growth rate of radial stress is much lower than that of inner radius. It should be noted that the maximum value of radial stress along middle circumference is not always increasing with the increasing of inner radius. The maximum value of radius stress decreases from 41.61MPa to $38.14 \mathrm{MPa}$ when inner radius increases from $5 \mathrm{~m}$ to $20 \mathrm{~m}$, while it increases from 40.61MPa to $69.08 \mathrm{MPa}$ when inner radius increases from $40 \mathrm{~m}$ to $100 \mathrm{~m}$. Meanwhile, the position of maximum value of radius stress is also different with different inner radius. Taking an example, the position of the maximum value of radial stress is located from $\theta=35^{\circ}$ to $\theta=0^{\circ}$ when the inner radius increases from $5 \mathrm{~m}$ to $100 \mathrm{~m}$. Therefore, we can get a conclusion that the maximum value of radius stress will move toward the open-off cut with the increasing of inner radius.

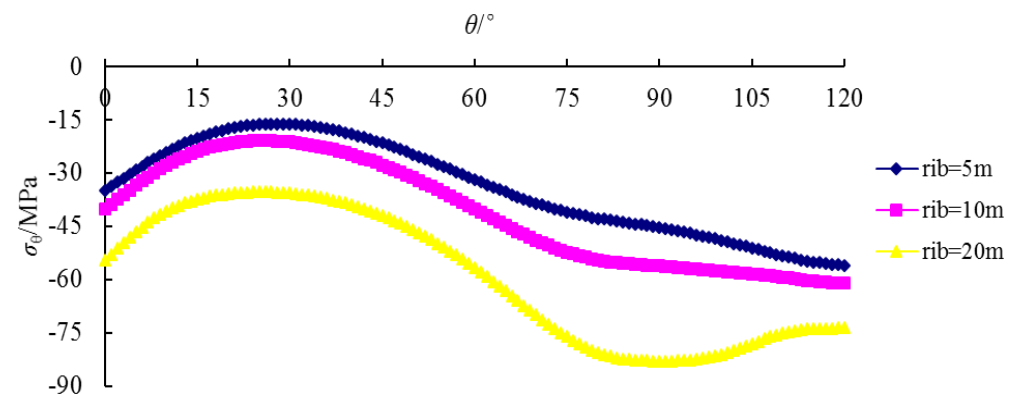

(a)

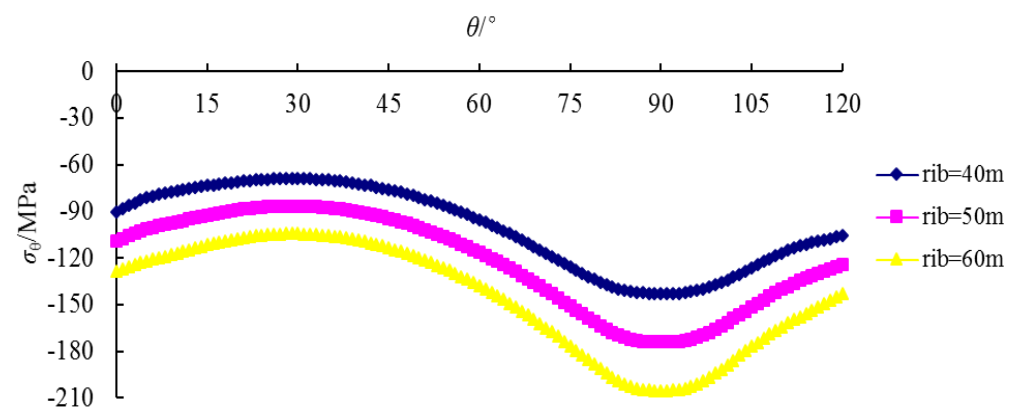


(b)

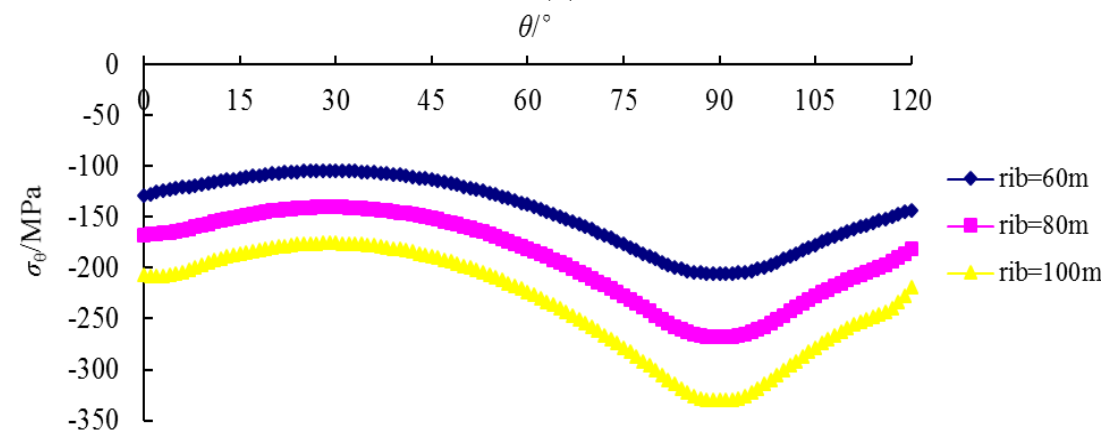

(c)

Fig.4 The circumferential stress distribution along middle circumference with different inner radii

According to Fig.4, it can be concluded that the curve of circumferential stress distribution is basically the same with different inner radius. With the increasing of inner radius, the value of circumferential stress increases gradually, as well as the peak value of circumferential stress. Taking an example, the peak value of circumferential stress increases from $60.99 \mathrm{MPa}$ to $329.94 \mathrm{MPa}$ when inner radius increases from $5 \mathrm{~m}$ to $100 \mathrm{~m}$. The circumferential stress increases about 4 times when the inner radius increases 19 times. Obviously, the growth rate of circumferential stress is much smaller than that of inner radius. It should be noteworthy that the peak position of circumferential stress is located at $\theta=90^{\circ}$ except the inner radius is $5 \mathrm{~m}$. The peak position of circumferential stress is easy to cause the circumferential compression damage in circular rock stratum. Thus, more observation and measures should be taken at the location of $\theta=90^{\circ}$ to avoid the disaster accidents in the mining process in circular rock stratum.

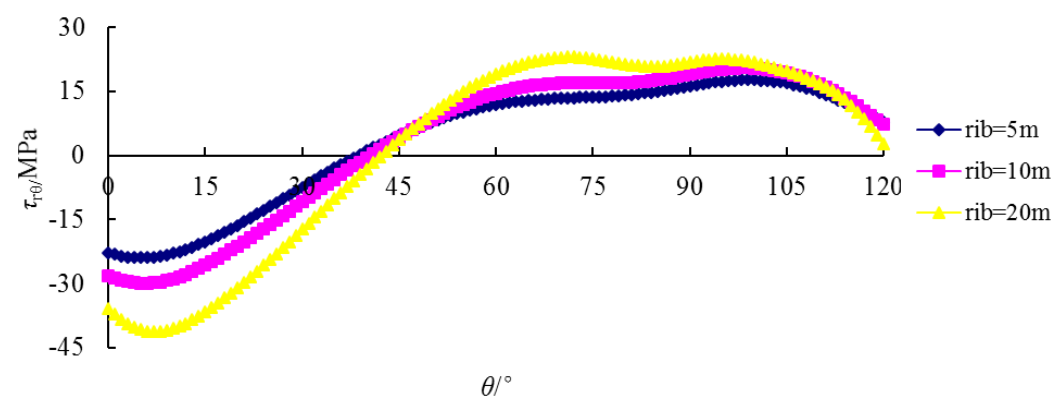

(a)

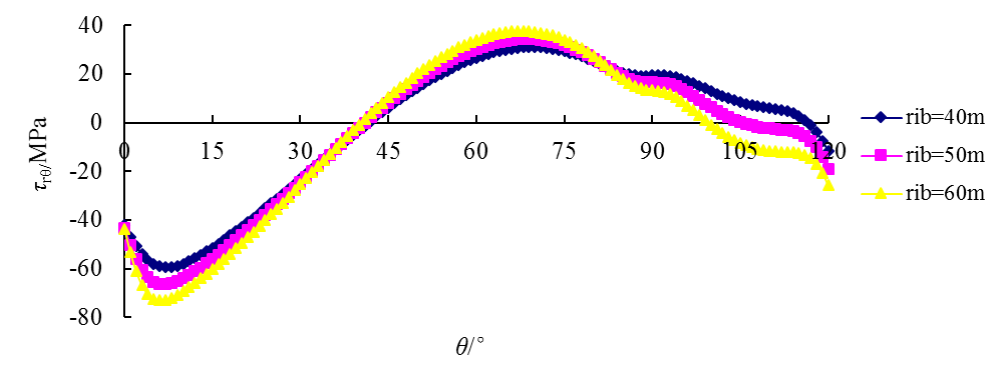

(b) 


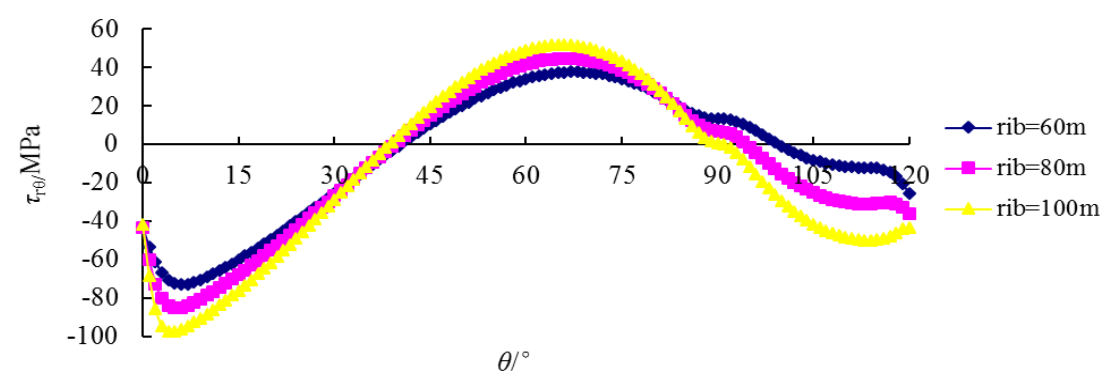

(c)

Fig. 5 The shear stress distribution along middle circumference with different inner radii

The peak value of shear stress basically increases with the increasing of inner radius in Fig.5. Giving an example, the peak value of shear stress increases from 23.97MPa to $97.65 \mathrm{MPa}$ when inner radius increases from $5 \mathrm{~m}$ to $100 \mathrm{~m}$. The shear stress increases about 3 times when the inner radius increases 19 times. Obviously, the growth rate of shear stress is also much smaller than that of inner radius. It is noteworthy that the shear stress on right boundary increases from $22.75 \mathrm{MPa}$ to $42.29 \mathrm{MPa}$ when the inner radius increases from $5 \mathrm{~m}$ to $40 \mathrm{~m}$, but it is stable at about $43 \mathrm{MPa}$ when the inner radius increases from $40 \mathrm{~m}$ to $100 \mathrm{~m}$. On the other hand, the shear stress on left boundary is increasing with the increasing of inner radius for inner radius being greater than $40 \mathrm{~m}$. Thus, it can be concluded that the effect of inner radius on shear stress is not significant for right boundary while it is significant for left boundary. The results also show that the peak position of shear stress is stable at $\theta=5^{\circ} \sim 6^{\circ}$ for different inner radii, which shows that the effect of inner radius on peak position of shear stress is not significant.

\subsubsection{The factor of tectonic stress coefficient}

Given that the inner radius $r_{i b}$ is $20 \mathrm{~m}$, the mining depth $m d$ is $1000 \mathrm{~m}$, the mining position $\theta_{i}$ is $0^{\circ}$, the advancing angle $\theta_{e}$ is $120^{\circ}$, the thickness of circular rock stratum $s t$ is $20 \mathrm{~m}$ and the tectonic stress coefficient $\lambda$ is assigned 1.2, 1.5, 1.8, 2.1 and 2.4, respectively. The stress components along middle circumference with different tectonic stress coefficients are analyzed as follows.

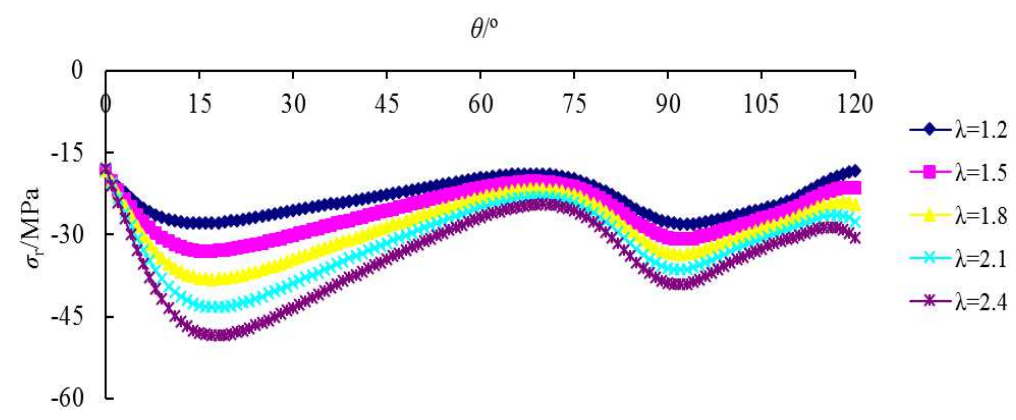

Fig.6 The distribution of radial stress along middle circumference with different tectonic stress coefficients

According to Fig.6, the curve of radial stress distribution is basically the same with different tectonic stress coefficients. The value of radial stress increases gradually with the increasing of tectonic stress coefficient, as well as the peak value of radial stress. Taking an example, the peak value of radial stress increases from $27.95 \mathrm{MPa}$ to $48.42 \mathrm{MPa}$ when tectonic stress coefficient increases from 1.2 to 2.4. The radial stress increases about $66 \%$ while tectonic stress coefficient increases 
$100 \%$. Hence, the growth rate of radial stress is smaller than that of tectonic stress coefficient. Moreover, the peak position of radial stress changes from $\theta=15^{\circ}$ to $\theta=18^{\circ}$ with the increasing of tectonic stress coefficient. It can be concluded that the peak position of radial stress will move toward to the working face with the increasing of tectonic stress coefficient, but doesn't significantly.

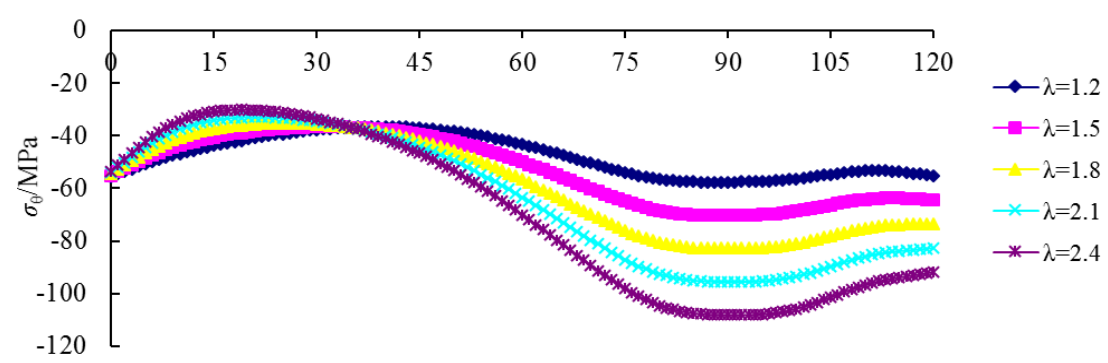

Fig.7 The circumferential stress distribution along middle circumference with different tectonic stress coefficients

The effect of tectonic stress coefficient on circumferential stress is not the same for all section according to the curves in Fig.7. The circumferential stress for sections $\left(\theta=0^{\circ} \sim 34^{\circ}\right)$ is decreasing while the circumferential stress for sections $\left(\theta=34^{\circ} \sim 120^{\circ}\right)$ is increasing with the increasing of tectonic stress coefficient. Taking an example, the circumferential stress on right boundary $\left(\theta=0^{\circ}\right)$ decreases from $55.67 \mathrm{MPa}$ to $53.59 \mathrm{MPa}$ when the tectonic stress coefficient increases from 1.2 to 2.4 , but the circumferential stress on left boundary $\left(\theta=120^{\circ}\right)$ increases from 55.19MPa to $91.79 \mathrm{MPa}$. It can be concluded that the circumferential stress around open-off cut will decrease with the increasing of tectonic stress coefficient, but the circumferential stress far away from open-off cut will increase. At the same time, the peak position of circumferential stress is also slightly different with the increasing of tectonic stress coefficient. The peak position changes from $\theta=88^{\circ}$ to $\theta=91^{\circ}$ when tectonic stress coefficient increases from 1.2 to 2.4 . It can be a conclusion that the peak value of circumferential stress will move toward to the working face, but it is not significant. Therefore, more observation and measures should be taken at the location about $\theta=90^{\circ}$ to avoid the disaster accidents in the mining process in circular rock stratum.

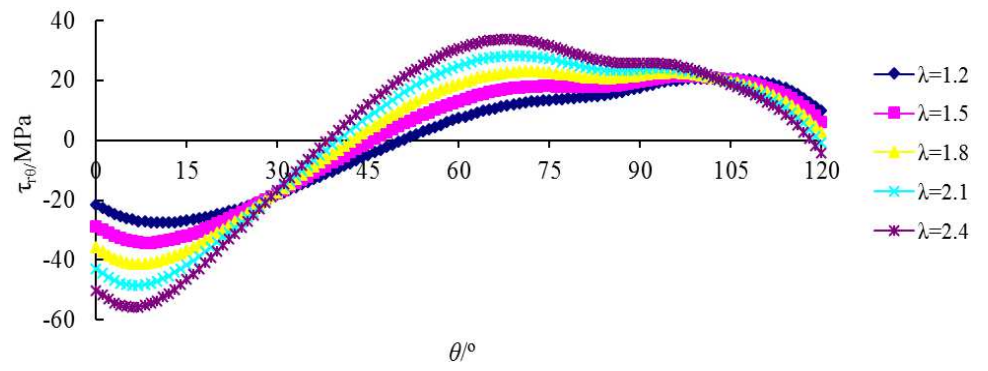

Fig. 8 The shear stress distribution along middle circumference with different tectonic stress coefficients

The effect of tectonic stress coefficient on shear stress is also not the same for all section according to the curves in Figure 14. The shear stress for sections $\left(\theta=0^{\circ} \sim 30^{\circ}\right.$ and $\left.\theta=45^{\circ} \sim 105^{\circ}\right)$ is increasing with the increasing of tectonic stress 
coefficient, but the shear stress for other sections is decreasing with the increasing of tectonic stress coefficient. Giving an example, the shear stress on right boundary $\left(\theta=0^{\circ}\right)$ increases from $21.53 \mathrm{MPa}$ to $50.15 \mathrm{MPa}$, while the shear stress on left boundary $\left(\theta=120^{\circ}\right)$ decreases from $9.85 \mathrm{MPa}$ to $-4.39 \mathrm{MPa}$ when the tectonic stress coefficient increases from 1.2 to 2.4. It indicates that the shear stress around openoff cut will increase with the increasing of tectonic stress coefficient, but the shear stress far away from open-off cut will decrease. Meanwhile, the peak position of shear stress is also different with the increasing of tectonic stress coefficient. The peak position changes from $\theta=11^{\circ}$ to $\theta=7^{\circ}$ when tectonic stress coefficient increases from 1.2 to 2.4. This result provides a conclusion that the peak value of shear stress will move toward to open-off cut, but it is not obvious.

\subsubsection{The factor of mining depth}

Given that the inner radius $r_{i b}$ is $20 \mathrm{~m}$, the tectonic stress coefficient $\lambda$ is 1.8 , the mining position $\theta_{i}$ is $0^{\circ}$, the advancing angle $\theta_{e}$ is $120^{\circ}$, the thickness of circular rock stratum $s t$ is $20 \mathrm{~m}$ and the mining depth $m d$ is assigned $600 \mathrm{~m}, 800 \mathrm{~m}, 1000 \mathrm{~m}, 1200 \mathrm{~m}$, and $1400 \mathrm{~m}$, respectively. The stress components along middle circumference with different mining depths are analyzed as follows.

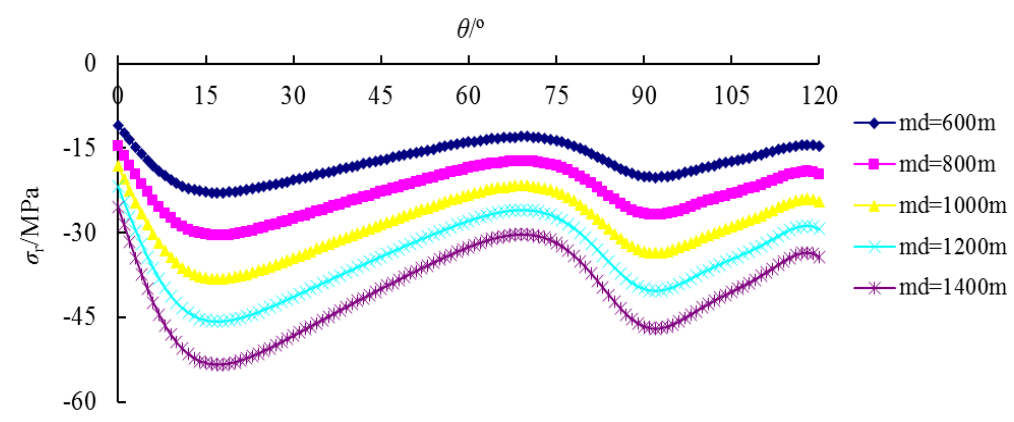

Fig.9 The radial stress distribution along middle circumference with different mining depths

According to Fig.9, the curve of radial stress distribution is basically the same with different mining depths. The value of radial stress increases gradually with the increasing of mining depth, as well as the peak value of radial stress. Taking an example, the peak value of radial stress increases from $22.88 \mathrm{MPa}$ to $53.39 \mathrm{MPa}$ when mining depth increases from $600 \mathrm{~m}$ to $1400 \mathrm{~m}$. The radial stress increases 1.33 times when mining depth also increases 1.33 times. Moreover, the radial stress on right or left boundary also increases 1.33 times with mining depth increasing 1.33 times. In fact, the radial stress in all sections increases 1.33 times with mining depth increasing 1.33 times. Therefore, there is a linear relationship between radial stress and mining depth. Meanwhile, the peak position of radial stress keeps in the same section $\left(\theta=17^{\circ}\right)$ with different mining depth. It can be a conclusion that the mining depth will don't change the peak position of radial stress. 


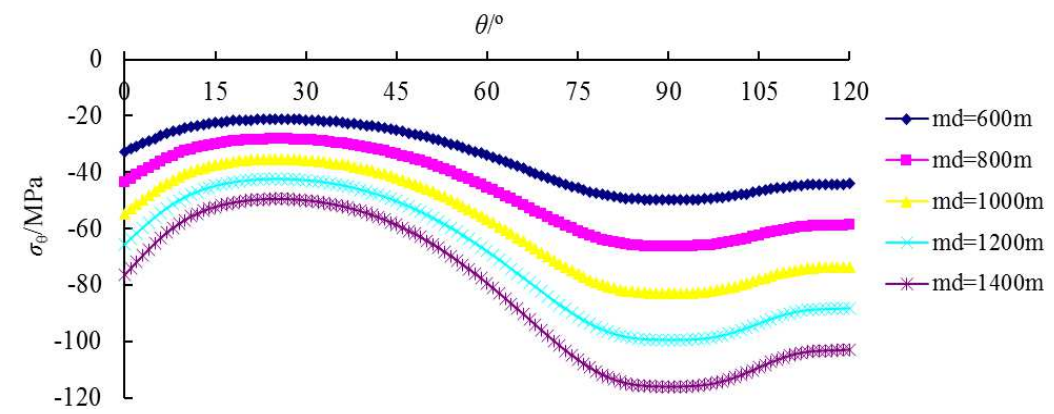

Fig.10 The circumferential stress distribution along middle circumference with different mining depths

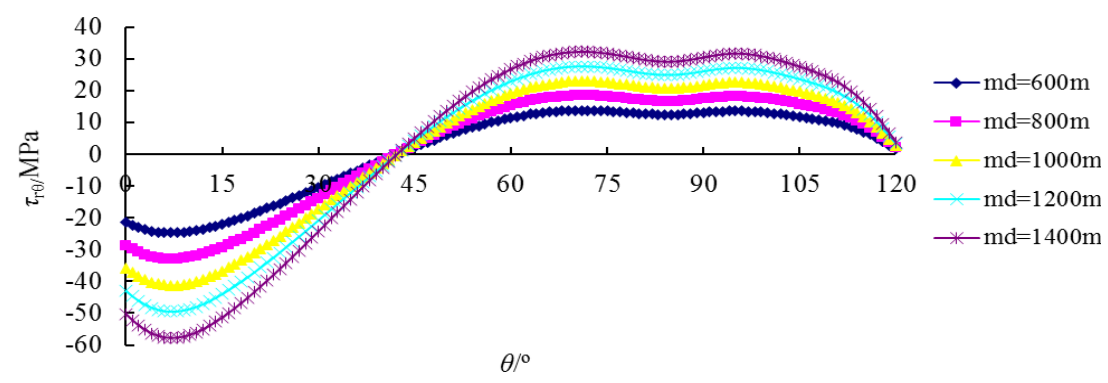

Fig.11 The shear stress distribution along middle circumference with different mining depths

According to Fig.10 and Fig.11, the effect of mining depth on circumferential stress or shear stress is the same as that of mining depth on radial stress. There is also a linear relationship between circumferential stress and mining depth or between shear stress and mining depth. Moreover, mining depth will also don't change the peak position of circumferential stress or shear stress.

\subsubsection{The factor of advancing angle}

Given that the inner radius $r_{i b}$ is $20 \mathrm{~m}$, the tectonic stress coefficient $\lambda$ is 1.8 , the mining depth $m d$ is $1000 \mathrm{~m}$, the mining position $\theta_{i}$ is $0^{\circ}$, the thickness of circular rock stratum $s t$ is $20 \mathrm{~m}$ and the advancing angle $\theta_{e}$ is assigned $30^{\circ}, 60^{\circ}, 90^{\circ}, 120^{\circ}, 150^{\circ}$ and $180^{\circ}$ respectively. The stress components along middle circumference with different advancing angles are analyzed as follows.

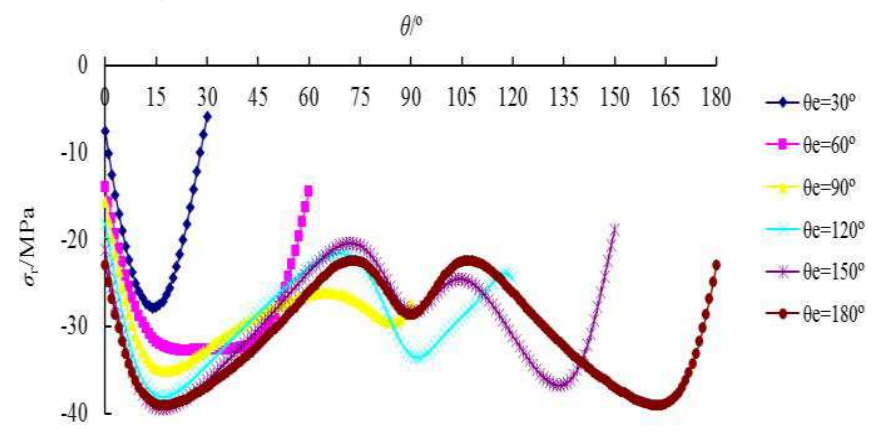

Fig.12 The radial stress distribution along middle circumference with different advancing angles

It can be shown that the variation of radial stress is not the same with different advancing angle in Fig.12. For example, the radial stress increases first and then decreases along circumferential direction when advancing angle is lower than $90^{\circ}$, while the radial stress increases and decreases alternately along circumferential direction when advancing angle is higher than $90^{\circ}$. Especially for advancing angle 
equaling to $180^{\circ}$, the distribution of radial stress is symmetrical when the loading and restrain conditions in numerical model are symmetrical. The peak value of radial stress is increasing with the increasing of advancing angle. Taking an example, the peak value of radial stress increases from 27.86MPa to $39.14 \mathrm{MPa}$ when advancing angle increases from $30^{\circ}$ to $180^{\circ}$. Obviously, advancing angle increases 5 times while the peak value of radial stress increases only $40 \%$. Therefore, the growth rate of radial stress is much lower than that of advancing angle. On the other hand, the peak position of radial stress is far away from open-off cut with the increasing of advancing angle, and then is stable at the section $\theta=17^{\circ}$.

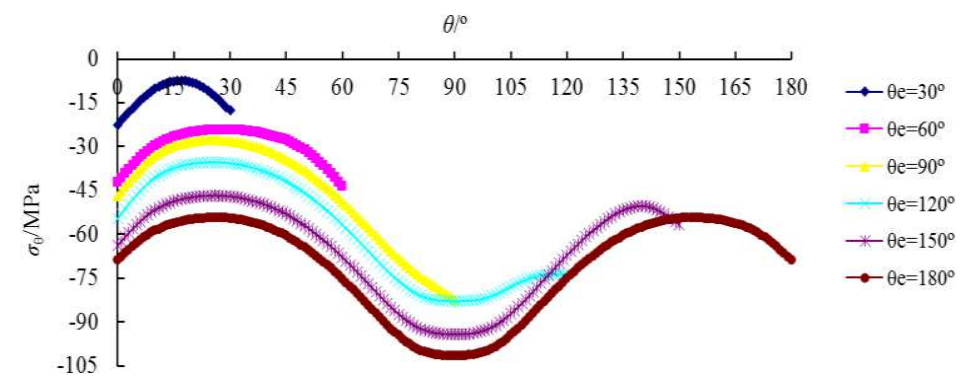

Fig.13 The circumferential stress distribution along middle circumference with different advancing angles

The variation of circumferential stress is not the same with different advancing angles shown in Fig.13. For example, the circumferential stress decreases first and then increases along circumferential direction when advancing angle is lower than $90^{\circ}$, while the circumferential stress decreases and increases alternately along circumferential direction when advancing angle is higher than $120^{\circ}$. Similarly with radial stress, the distribution of circumferential stress is also symmetrical with symmetrical boundary conditions for advancing angle equaling to $180^{\circ}$. The value of circumferential stress increases gradually with the increasing of advancing angle, as well as the peak value of circumferential stress. Giving an example, the peak value of circumferential stress increases from $22.61 \mathrm{MPa}$ to $101.62 \mathrm{MPa}$ when advancing angle increases from $30^{\circ}$ to $180^{\circ}$. The advancing angle increases 5 times when the peak value of circumferential stress increases 3.5 times. Thus, advancing angle is not only affecting the distribution of circumferential stress, but also significantly affecting the value of circumferential stress. Meanwhile, the peak position of circumferential stress is not the same with the increasing of advancing angle. The peak value of circumferential stress is at right boundary for advancing angle being lower than $60^{\circ}$, but the peak value of circumferential stress is at the section $\theta=90^{\circ}$ for advancing angle being higher than $60^{\circ}$. Therefore, more observation and measures should be taken at open-off cut when advancing angle is lower than $60^{\circ}$, while more observation and measures should be taken at the section $\theta=90^{\circ}$ when advancing angle is higher than $60^{\circ}$. 


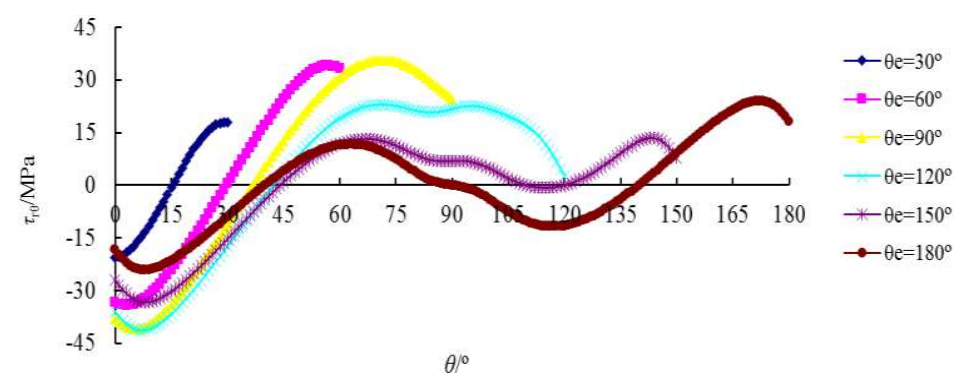

Fig.14 The shear stress distribution along middle circumference with different advancing angles

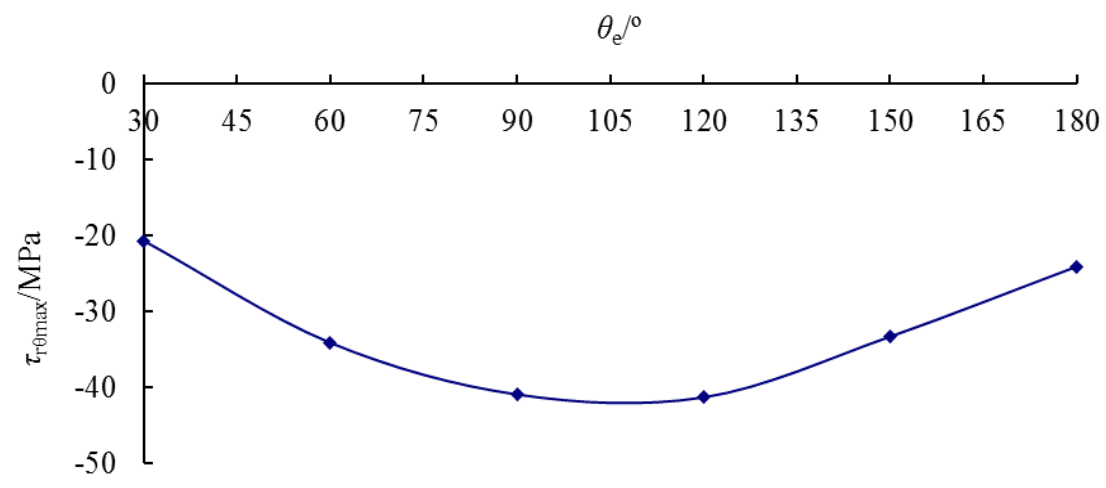

Fig.15 The relationship between the peak value of shear stress and advancing angle

According to Fig.14, the shear stress increases and decreases alternately along circumferential direction, especially for high advancing angle. Contrary to radial stress and circumferential stress, the distribution of shear stress is antisymmetric with symmetrical boundary conditions for advancing angle equaling to $180^{\circ}$. Fig. 15 shows the relationship between the peak value of shear stress and advancing angle. It can be a conclusion that the peak value of shear stress increases fist and then decreases with the increasing of advancing angle. At the same time, the peak position of shear stress changes from $\theta=0^{\circ}$ to $\theta=8^{\circ}$ with advancing angle increasing from $30^{\circ}$ to $180^{\circ}$. It can be a conclusion that the peak value of shear stress tends to far away from the openoff cut, but it is not significant.

\subsubsection{The factor of mining position}

Given that the inner radius $r_{i b}$ is $20 \mathrm{~m}$, the tectonic stress coefficient $\lambda$ is 1.8 , the mining depth $m d$ is $1000 \mathrm{~m}$, the advancing angle $\theta_{e}$ is $120^{\circ}$, the thickness of circular rock stratum $s t$ is $20 \mathrm{~m}$ and the mining position $\theta_{i}$ is assigned $0^{\circ}, 15^{\circ}, 30^{\circ}, 45^{\circ}$ and $60^{\circ}$ respectively. The stress components along middle circumference with different mining positions are analyzed as follows. In this part, we analyze the sections with the same angle from right boundary for different mining positions in numerical model, which is defined as $\theta-\theta_{i}$.

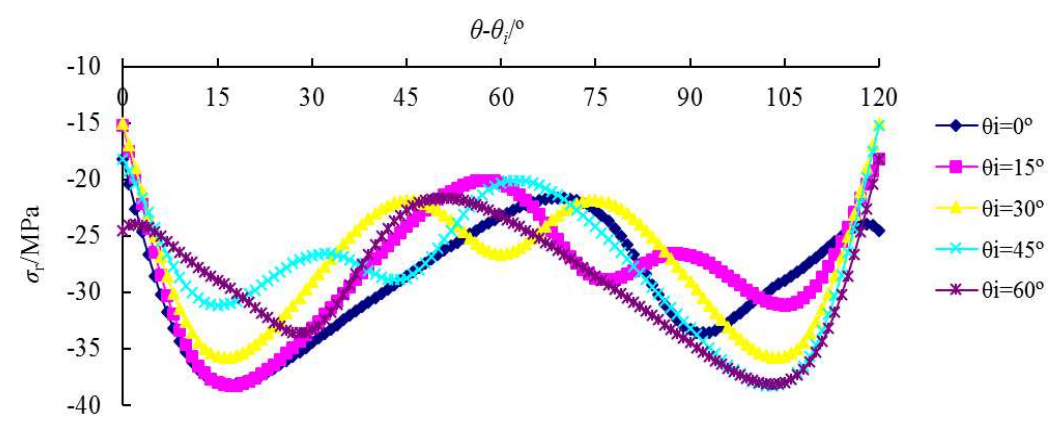


Fig. 16 The radial stress distribution along middle circumference with different mining positions

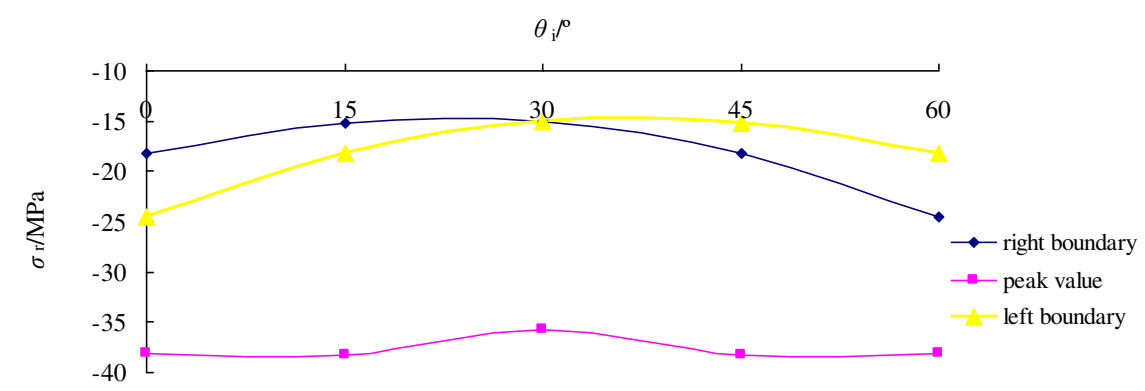

Fig.17 The variation of radial stress with different mining positions

According to Fig.16, the radial stress increases and decreases alternately along circumferential direction. The radial stress in some sections increases with the increasing of mining position, it decreases with the increasing of mining position in some sections, and it also increases and decreases alternately with the increasing of mining position in some other sections. Here, we mainly analyze the radial stress at right and left boundary and the peak value of radial stress, which is shown in Fig.17. It can be shown that the radial stresses in these three sections are all decrease first and then increase with the increasing of mining position. Obviously, the radial stress is to the minimum when mining position is at the angle $30^{\circ}$. In fact, distribution of radial stress is symmetrical with the symmetrical loadings and restrains in numerical model when mining position is at the angle of $30^{\circ}$. Therefore, the open-off cut should be located around the angle of $30^{\circ}$ for coal mining in circular rock stratum. It should be noted that there are two equal peak values of radial stresses when mining position is at the angle of $30^{\circ}$, which is at the angle of $16^{\circ}$ from right and left boundary, respectively. The peak position is close to the open-off cut when mining position is lower than the angle of $30^{\circ}$, while it is close to the working face when mining position is higher than the angle of $30^{\circ}$.

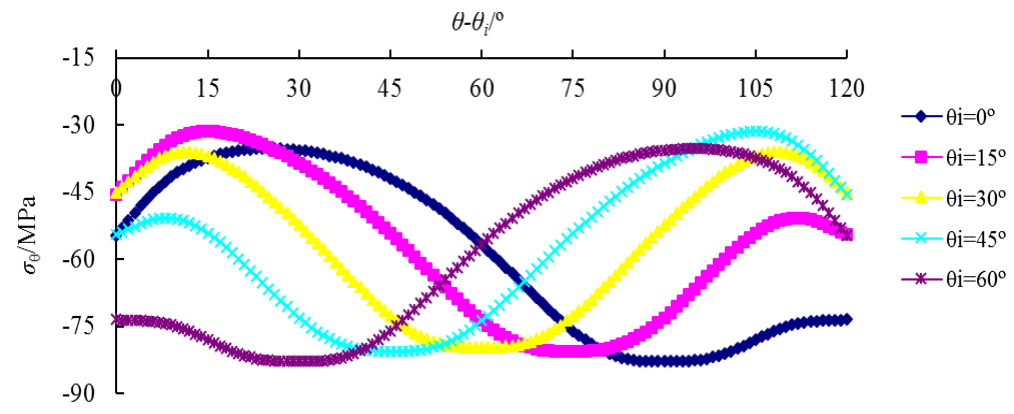

Fig. 18 The circumferential stress distribution along middle circumference with different mining positions 


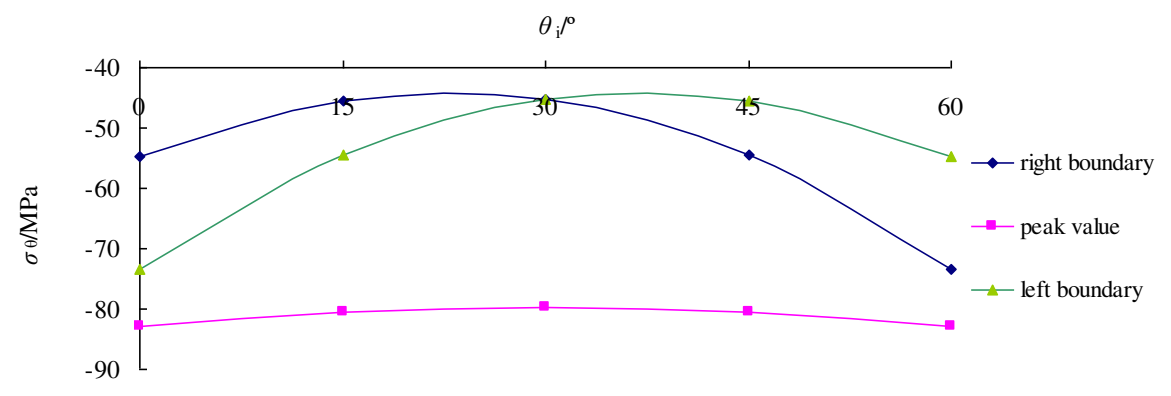

Fig.19 The variation of circumferential stress with different mining positions

The circumferential stress decreases and increases alternately along circumferential direction as being shown in Fig.18. Similarly with radial stress, the circumferential stress increases with the increasing of mining position in some sections, and it decreases with the increasing of mining position in some other sections, and it also increases and decreases alternately with the increasing of mining position in some sections. Here, we also mainly analyze the circumferential stress at right and left boundary and the peak value of circumferential stress, which is shown in Fig. 19. It can be seen that the circumferential stresses in these three sections are all decrease first and then increase with the increasing of mining position. The circumferential stress is to the minimum when mining position is at the angle of $30^{\circ}$, which is the same variation as radial stress. Therefore, the open-off cut should be located around the angle of $30^{\circ}$ for coal mining in curved stratum. It should be noted that the peak values of circumferential stress are all at the highest point of the numerical model with different mining positions. Taking an example, the peak values of circumferential stress are located at the angle of $75^{\circ}$ from the right boundary when mining position is the angle $15^{\circ}$, which is the highest point in this numerical model. Therefore, more observation and measures should be taken at the anticline ridge in circular rock stratum during the working face advancing.

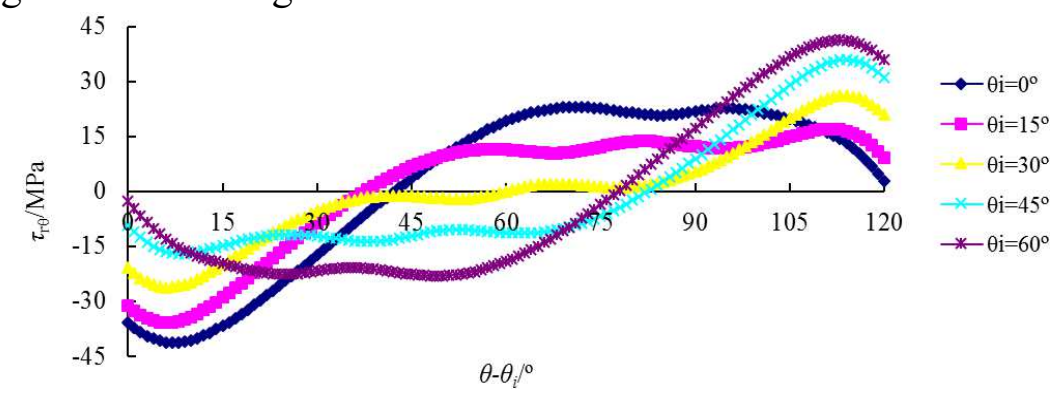

Fig.20 The shear stress distribution along middle circumference with different mining positions 


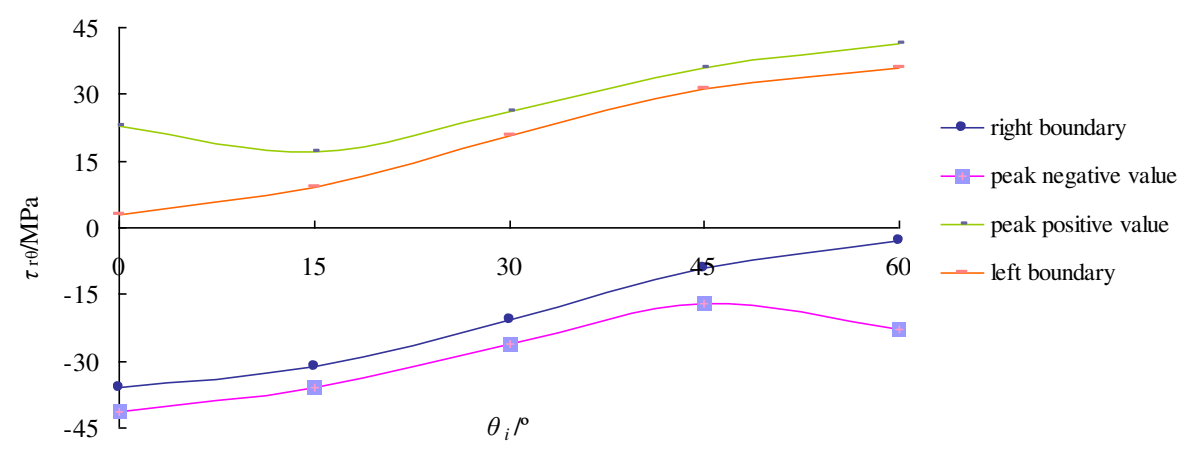

Fig.21 The variation of shear stress with different mining positions

The shear stress decreases and increases alternately along circumferential direction as being seen in Fig.20. It is obvious that there are negative value and positive value for shear stress. Similarly with radial stress and circumferential stress, the shear stress increases with the increasing of mining position in some sections, it decreases with the increasing of mining position in some other sections, and it increases and decreases alternately with the increasing of mining position in some sections. Here, we also mainly analyze the shear stress at right and left boundary and the peak value of shear stress, which is shown in Fig.21. The peak value of shear stress includes peak negative value and peak positive value. It can be concluded that the peak negative value is decreasing with the increasing of mining position, while the peak positive value is increasing with the increasing of mining position. The feasible position for open-off cut is at the angle of $30^{\circ}$ in circular rock stratum. The peak position of negative value is located at the angle of $6^{\circ} \sim 7^{\circ}$ from right boundary when mining position is in range of $0^{\circ} \sim 45^{\circ}$, but the peak position of negative value is located at the angle of $49^{\circ}$ from right boundary when mining position is at the angle of $60^{\circ}$. The variation law of peak position of positive value is just the opposite with the peak position of negative value. Therefore, mining position has significant effect on the peak position of shear stress.

\subsubsection{The factor of thickness of circular rock stratum}

Given that the inner radius $r_{i b}$ is $20 \mathrm{~m}$, the tectonic stress coefficient $\lambda$ is 1.8 , the mining depth $m d$ is $1000 \mathrm{~m}$, the advancing angle $\theta_{e}$ is $120^{\circ}$, the mining position $\theta_{i}$ is $0^{\circ}$ and the thickness of circular rock stratum $s t$ is assigned $10 \mathrm{~m}, 15 \mathrm{~m}, 20 \mathrm{~m}, 25 \mathrm{~m}$ and $30 \mathrm{~m}$ respectively. The stress components along middle circumference with different thicknesses of circular rock stratum are analyzed as follows.

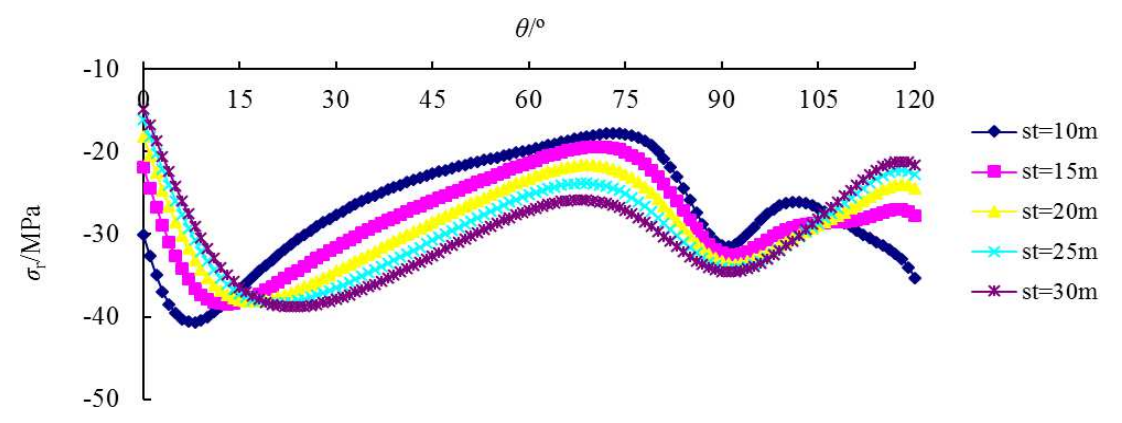


Fig.22 The radial stress distribution along middle circumference with different thicknesses of circular rock stratum

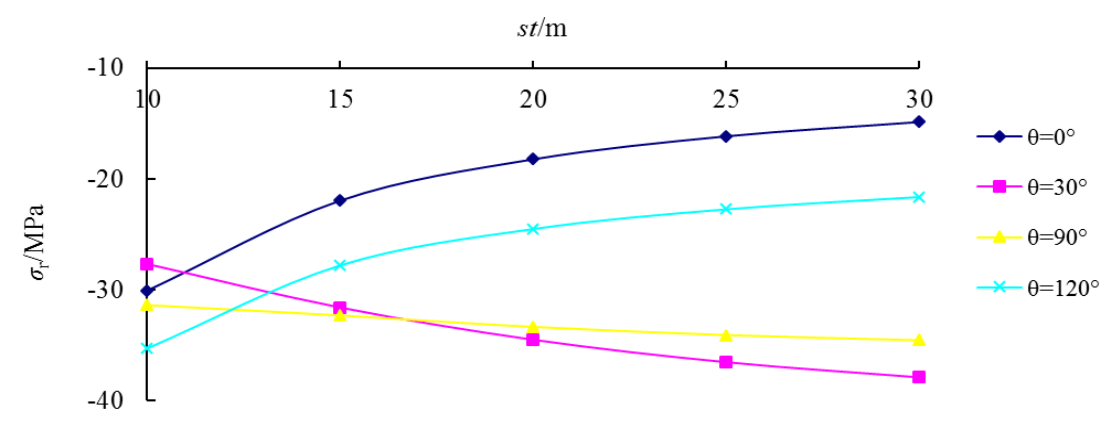

Fig.23 The radial stress distribution with different thicknesses of circular rock stratum for four different sections

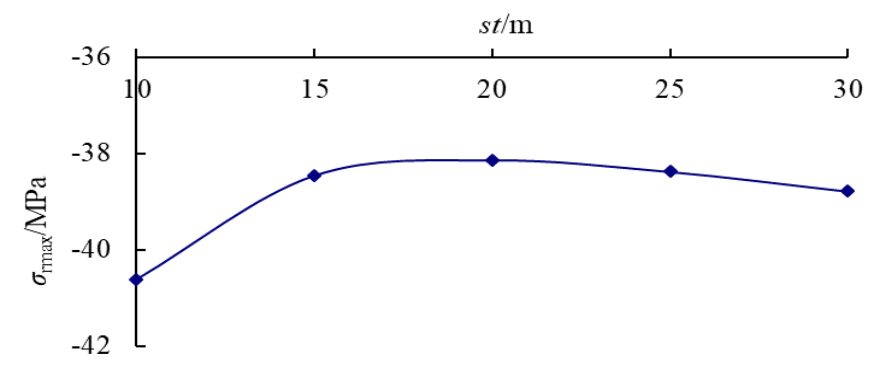

Fig.24 The variation of peak radial stress with different thicknesses of circular rock stratum

According to Fig.22, the radial stress increases and decreases alternately along circumferential direction. The radial stress increases with the increasing of thickness of circular rock stratum in some sections, while it decreases with the increasing of thickness of circular rock stratum in some other sections. Fig.23 shows the radial stress distribution with different thicknesses of circular rock stratum at four different sections $\left(\theta=0^{\circ}, 30^{\circ}, 90^{\circ}, 120^{\circ}\right)$. It can be seen that radial stress around right $\left(\theta=0^{\circ}\right)$ or left boundary $\left(\theta=120^{\circ}\right)$ decreases with the increasing of thickness of circular rock stratum, but the radial stress at the angle of $30^{\circ}$ or $90^{\circ}$ increases with the increasing of thickness of circular rock stratum. In fact, the radial stresses at the angle range of $30^{\circ} \sim 90^{\circ}$ both increase with the increasing of thickness of circular rock stratum. Fig. 24 shows variation of the peak value of radial stress with different thicknesses of circular rock stratum. Obviously, the peak value of radial stress decreases first and then increase with the increasing of thickness of circular rock stratum. The peak value of radial stress is to minimum when the thickness of circular rock stratum is $20 \mathrm{~m}$. On the other hand, the peak position of radial stress will move toward to the working face with the increasing of thickness of circular rock stratum, but not significantly. For example, the peak position of radial stress changes from $\theta=8^{\circ}$ to $\theta=23^{\circ}$ when the thickness of circular rock stratum increases from $10 \mathrm{~m}$ to $30 \mathrm{~m}$. 


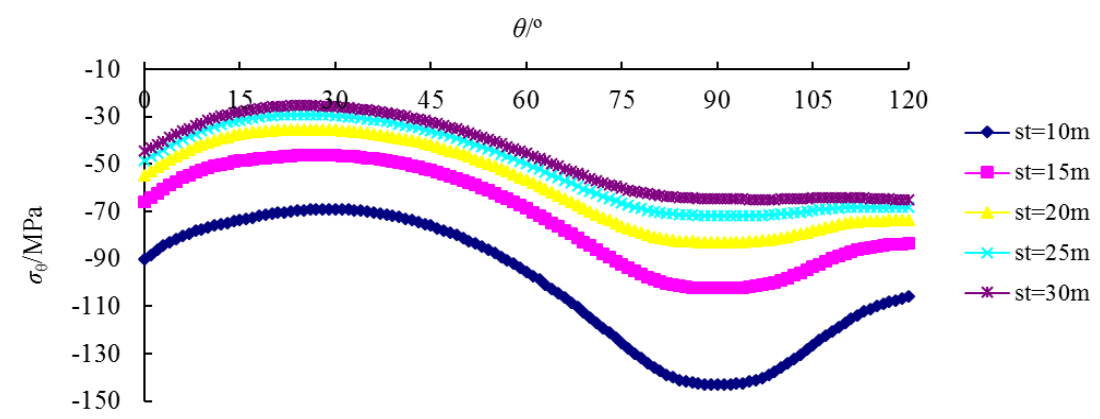

Fig.25 The circumferential stress distribution along middle circumference with different thicknesses of circular rock stratum

Fig. 25 shows the variation of circumferential stress with different thicknesses of circular rock stratum. Obviously, the circumferential stress decreases and increases alternately along circumferential direction. The circumferential stress decreases with the decreasing of thickness of circular rock stratum, as well as the peak value of circumferential stress. Taking an example, the peak value of circumferential stress decreases from $142.85 \mathrm{MPa}$ to $64.83 \mathrm{MPa}$ when the thickness of circular rock stratum increases from $10 \mathrm{~m}$ to $30 \mathrm{~m}$. Meanwhile, the peak position of circumferential stress changes from $90^{\circ}$ to $97^{\circ}$ with the thickness of circular rock stratum increasing from $10 \mathrm{~m}$ to $30 \mathrm{~m}$. It can be concluded that the increasing of thickness of circular rock stratum will make the peak position of circumferential stress move toward to the working face, but not significantly. Therefore, the increasing of thickness of circular rock stratum plays a positive role in reducing the circumferential stress, and the peak position of circumferential stress is always around the angle of $90^{\circ}$. More observation and measures should be taken at the location about $\theta=90^{\circ}$ to avoid the disaster accidents in the mining process in circular rock stratum.

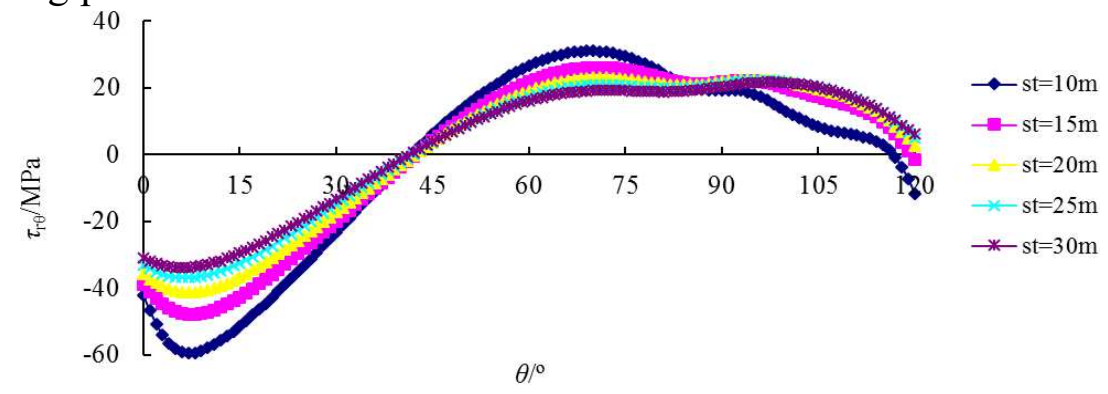

Fig.26 The shear stress distribution along middle circumference with different thicknesses of circular rock stratum

The shear stress increases and decreases alternately along circumferential direction as being shown in Fig.26. The shear stress at the angle range of $0^{\circ} \sim 90^{\circ}$ decreases with the increasing of thickness of circular rock stratum, as well as the peak value of shear stress, but it decreases with the increasing of thickness of circular rock stratum at the angle range of $90^{\circ} \sim 120^{\circ}$. Taking an example, the peak value of shear stress decreases from $59.43 \mathrm{MPa}$ to $33.85 \mathrm{MPa}$ with the thickness of circular rock stratum increasing from $10 \mathrm{~m}$ to $30 \mathrm{~m}$. On the other hand, the peak position of shear stress almost doesn't change and is stable at the angle range of $6^{\circ} \sim 7^{\circ}$. Therefore, it can be concluded that the thickness of circular rock stratum plays a positive role in reducing the value of shear stress, but has not significant effect on the peak position 
of shear stress.

\section{Field application in fold structure}

\subsection{Geological conditions in a mining area}

There is a mining area numbered 2502 with the surface level in the range of $+1509 \mathrm{~m} \sim+1603 \mathrm{~m}$ and the coal seam level in the range of $+860 \mathrm{~m} \sim+1200 \mathrm{~m}$ in China. The thickness of No.2502 coal seam is in the range of $18.2 \mathrm{~m} \sim 54.5 \mathrm{~m}$ and its average thickness is about $31 \mathrm{~m}$. The geological conditions in No.2502 mining area are more complicated for rock stratum lithology and geological structure, especially for fold structure. The syncline and anticline are alternately distributed from north to south with a distance of $2600 \mathrm{~m}$ in No.2502 mining area. Full-mechanized caving mining method is adopted for coal extractions along these fold structure of syncline and anticline. Fig. 27 shows the part of geological sections in No.2502 mining area.

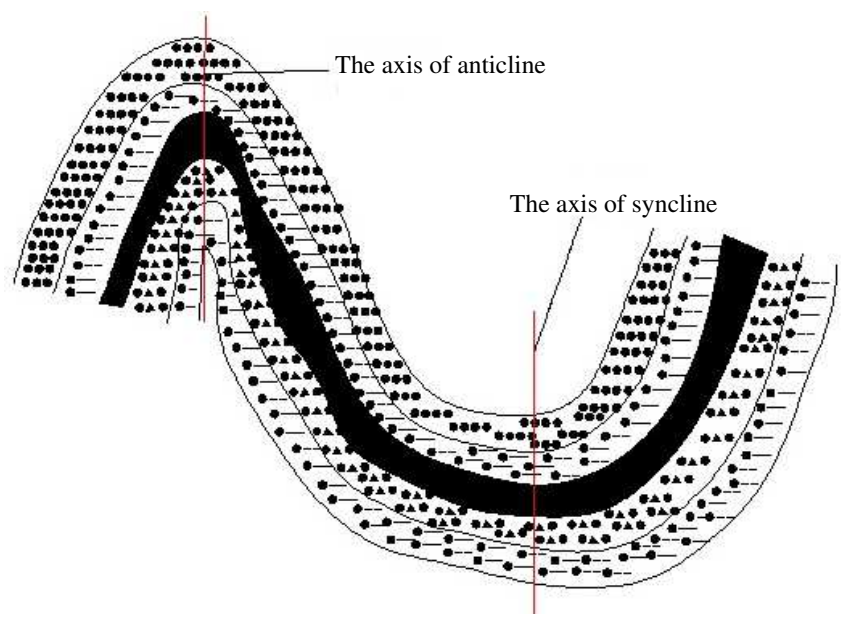

Fig.27 The part of geological sections in No.2502 mining area

\subsection{Numerical Model for a circular arc-shaped fold structure}

The Schematic diagram of coal extractions are established as shown in Fig.28 according to the geological conditions in No.2502 mining area. Here, the fold structure is simplified as circular arc shape with the similar simplifying method in section 3. The open-off cut is located at the groove point of syncline, and then the working face is pushed up to ridge point of anticline. The research object is first stratum above the goaf, which is the red region in Fig.28. The numerical model for computation with plane strain problem is given in Fig.29, and the boundary conditions of displacement restrain and stress restrain are also shown in Fig.29. The mining depth is $1000 \mathrm{~m}$, the thickness of rock stratum is $16.8 \mathrm{~m}$, and the tectonic stress coefficient $\lambda$ is equal to 2 . The radius of rock stratum at lower boundary in syncline is $56.8 \mathrm{~m}$, and the radius of rock stratum at lower boundary in anticline is $40 \mathrm{~m}$. The mesh length in radial direction and circumferential direction is $0.4 \mathrm{~m}$ and $1^{\circ}$ respectively. The physical and mechanical parameters of rock stratum are shown in Table 3. 


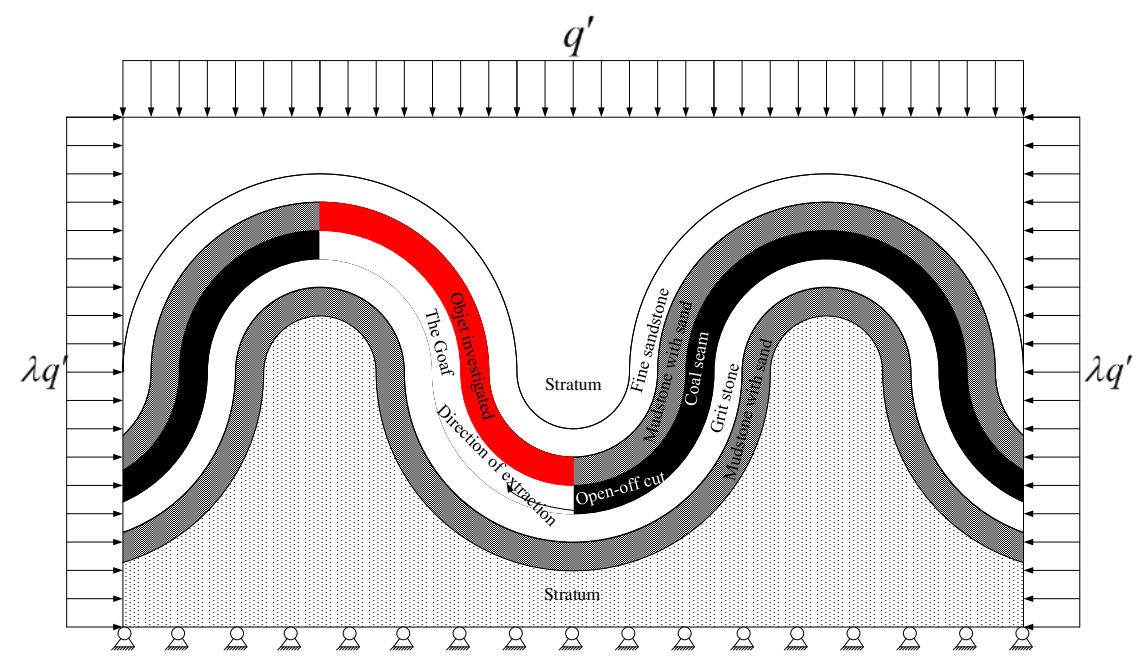

Fig.28 Schematic diagram of coal extractions in No.2502 mining area

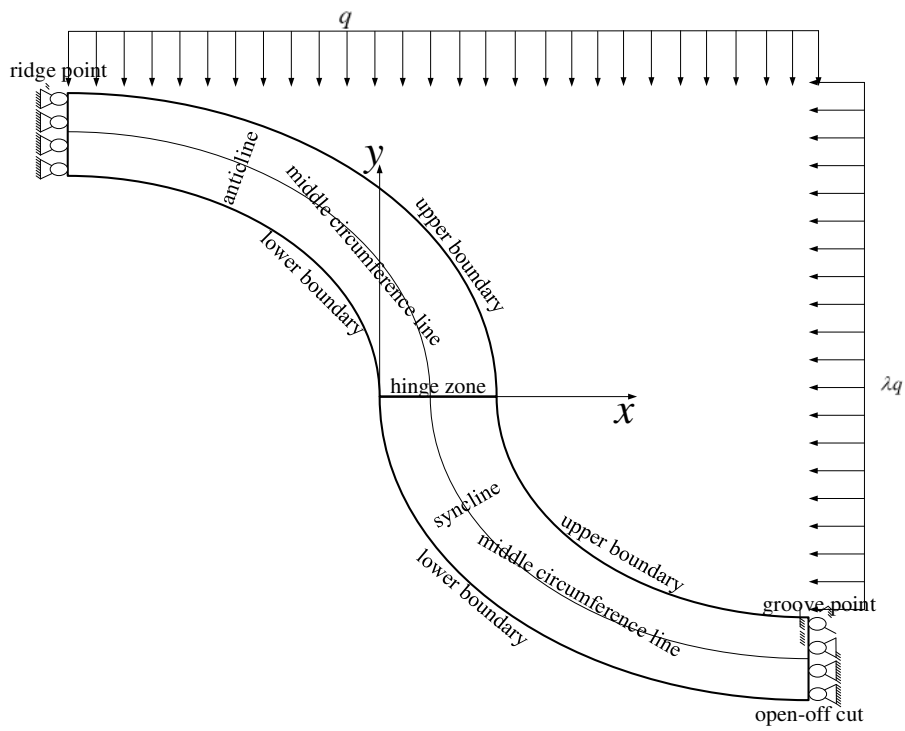

Fig.29 Numerical model of coal extractions from syncline to anticline

Table 3 Physical and mechanical parameters of rock stratum

\begin{tabular}{ccc}
\hline Young's modulus /(GPa) & Poisson's ratio $\mu$ & density $/\left(\mathrm{kg} \cdot \mathrm{m}^{-3}\right)$ \\
\hline 18 & 0.185 & 2400 \\
\hline
\end{tabular}

\subsection{Stress analysis for circular rock stratum}

In this section, the stress components are analyzed with the working face being pushed up to a distance of $30 \mathrm{~m}, 60 \mathrm{~m}, 90 \mathrm{~m}, 110 \mathrm{~m}, 130 \mathrm{~m}$ and $150 \mathrm{~m}$. For feasible analysis, the numerical calculation results in polar coordinates are converted to that in Cartesian coordinates by coordinate transformation method. The distribution of horizontal stress $\sigma_{x}$, vertical stress $\sigma_{y}$, and shear stress $\tau_{x y}$ are shown as follows.

According to Fig.30, it can be seen that the horizontal stresses along middle circumference line are not uniformly distributed along the direction of pushing up, which present alternately changing between decreasing and increasing. Almost half of the horizontal stresses are the tensile stresses and half are the compressive stresses with different advancing distances. The tensile stresses are mainly distributed in the rock stratum ahead of the open-off cut while the compressive stresses are mainly distributed 
in the rock stratum behind of the working face. The maximum value of horizontal tensile stress is about 1.43 times that of in-situ stress in the rock stratum ahead of the open-off cut, which easily leads to tensile fracture for the brittle material of rock stratum. Meanwhile, the maximum value of horizontal compressive stress is about 1.75 times that of in-situ stress in the rock stratum behind of the working face, which leads to compressive damage for rock stratum. These conclusions are basically consistent with the actual breaking of fold structure in No.2502 mining area.

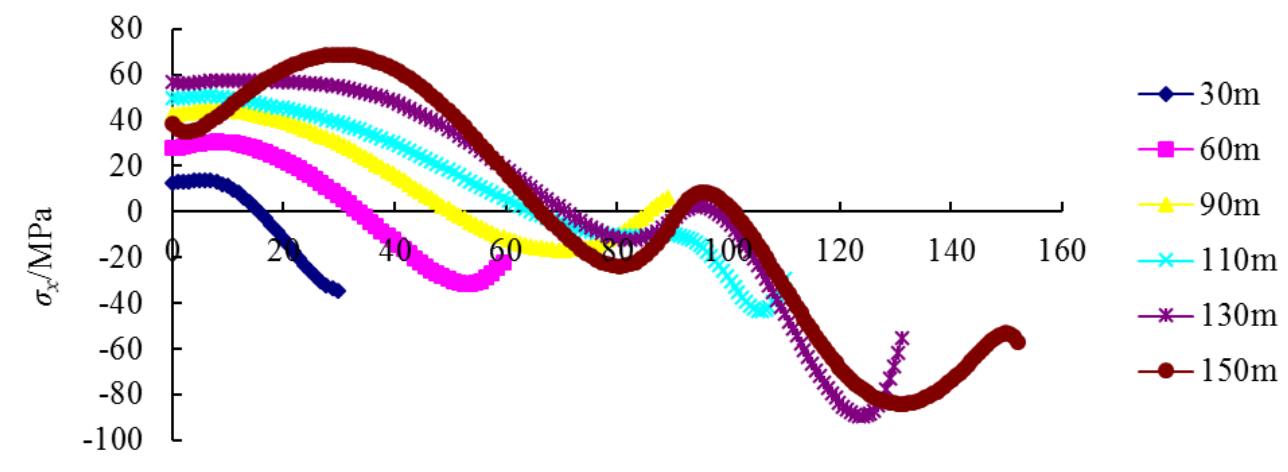

The distance to open-off cut $/ \mathrm{m}$

Fig.30 The horizontal stress distribution along middle circumference line with different advancing distances

Fig. 31 shows the vertical stress distributions along middle circumference line with different advancing distances and the vertical stresses along middle circumference line also present alternately changing between increasing and decreasing. The vertical stresses are mainly tensile stresses with different advancing distances. The maximum value of vertical tensile stress is mainly distributed in the rock stratum behind of the working face, and it is about 3.71 times that of in-situ stress, which easily leads to tensile fracture for the brittle material of rock stratum. On the other hand, by comparing with other advancing distances, the vertical tensile stresses are relatively reducing when the advancing distance is equal to $150 \mathrm{~m}$ which is at the location of ridge point of anticline. Therefore, these results show that the vertical tensile stress is relatively large in rock stratum for the working face before reaching the ridge point of anticline, while it will decrease when the working face reaches at or passes the ridge point of anticline. Thus, it can be concluded that the working face should pass the ridge point of anticline quickly in the process of coal extractions for avoiding rock stratum breaking under conditions of vertical tensile stress.

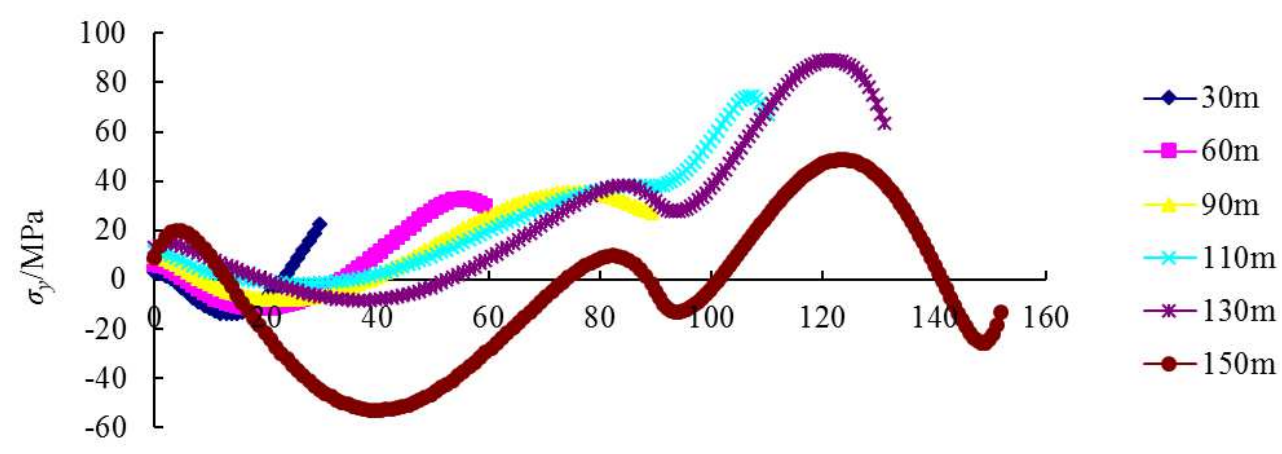

The distance to open-off cut $/ \mathrm{m}$ 
Fig.31 The vertical stress distribution along middle circumference line with different advancing distances

It can be seen that the shear stresses along middle circumference line are not uniformly distributed along the direction of pushing up and also change alternately between increasing and decreasing according to Fig.32. The maximum value of shear stress is mainly distributed in the rock stratum behind of the working face with different advancing distances. Thus, there may be shear damage or shear failure in the rock stratum behind of the working face in the process of coal extractions.

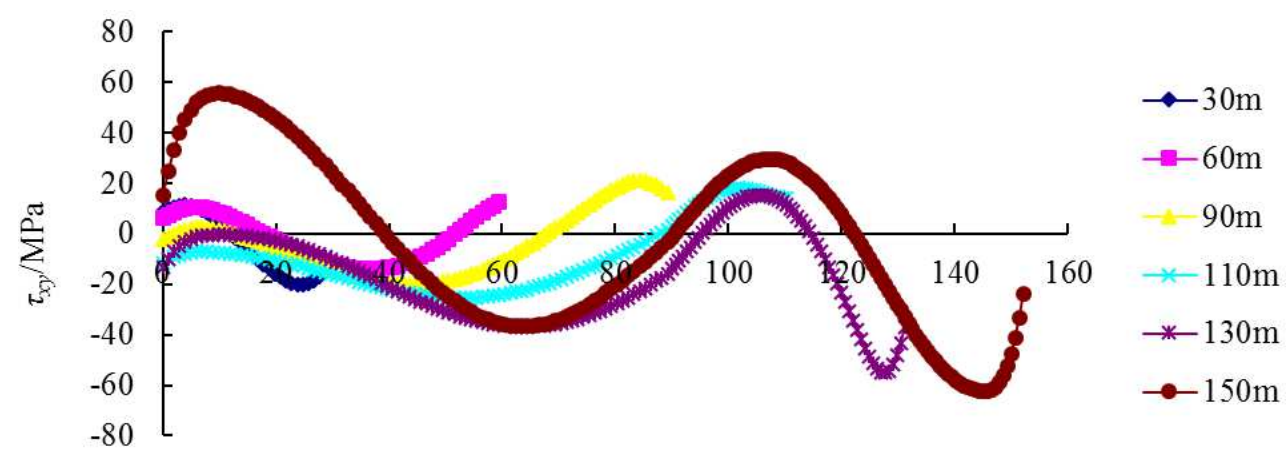

The distance to open-off cut $/ \mathrm{m}$

Fig.32 The shear stress distribution along middle circumference line with different advancing distances

\section{Conclusions}

A displacement function is presented in polar coordinates for solving two partial differential equations with the boundary conditions in mixed type in elastic, isotropic and homogeneous rock. Subsequently, the displacement function is governed by a single fourth-order elliptic partial differential equation of equilibrium and its numerical solutions are obtained by a finite-difference computation. The variations of stress distribution with different influencing factors are analyzed according to the analytical expression of stress components in terms of displacement function, which may lead to a better understanding of the stability of circular rock stratum after coal extractions. Finally, this semi-analytical elastic stress solution is applied to the fold structure in No.2502 mining area and points out the dangerous sites during coal extractions, which provides the basis of construction and safety in coal mine engineering.

\section{Acknowledgements}

The authors are grateful for the referee's constructive comments that improving the presentation of this paper.

\section{Funding}

Project ZR2020ME100 supported by Shandong Provincial Natural Science Foundation and Project XY19BS23 supported by Research Foundation of Heze University are gratefully acknowledged.

\section{References}

Ahmed S R, Idris A B M, Uddin M W. Numerical solution of both ends fixed deep beams[J]. Computers \& Structures, 1996, 61(1):21-29.

Ahmed S R, Khan M R, Islam K M S, Uddin M W. Investigation of stresses at the fixed end of deep cantilever beams[J].Computers \& Structures, 1998,69(1):329-338. 
Ahmed S R, Hossain M Z, Uddin M W.A general mathematical formulation for finite-difference solution of mixedboundary-value problems of anisotropic materials[J]. Computers \& structures, 2005, 83(1): 35-51.

Bagci C. A new unified strength of materials solution for stresses in curved beams and rings[J]. Journal of Mechanical Design, 1992,114(2):231-237.

Bagci C. Exact elasticity solutions for stresses and deflections in curved beams and rings of exponential and Tsections[J]. Journal of Mechanical Design,1993,115(3):346-358.

Chianese R B, Erdlac R J. The general solution to the distribution of stresses in a circular ring compressed by two forces acting along a diameter[J]. The Quarterly Journal of Mechanics and Applied Mathematics, 1988, 41(2):239-247.

Cook R D. Circumferential stress in curved beams[J]. The American Society of Mechanical Engineers, 1992,59(1):224-225.

Cook R D. Axisymmetric finite element analysis for pure moment loading of curved beams and pipe bends[J]. Comput. \& Structures, 1989, 33(2):483-487.

Durelli A J, Ranganayakamma B. Parametric solution of stresses in beams[J]. Journal of Engineering Mechanics, 1989,115(2):401-415.

Dow J O, Jones M S, Harwood S A. A new approach to boundary modeling for finite difference applications in solid mechanics[J]. International Journal for Numerical Methods in Engineering, 1990, 30(1):99-113.

Gangan P. The curved beam/deep arch/finite ring element revisited[J]. International Journal for Numerical Methods in Engineering, 1985, 21(3):389-407.

$\mathrm{Hu}$ W.Y., He M.C. The present situation and development trend for deep coal resources and the development of geological conditions[M]. Beijing: Coal Industry Publishing House, 2008.

He M.C., Qian Q.H. Mechanical foundation for deep rock mass[M]. Beijing: Science Press, 2010.

Ranzi G, Gara F, Leoni G, Bradford M A. Analysis of composite beams with partial shear interaction using available modeling techniques: A comparative study[J]. Computers \& structures, 2006, 84(13-14): 930-941.

Oden J T, Ripperger E A. Mechanics of Elastic Structures, second ed[M]. New York: McGraw-Hill Book Company,1981.

Rattanawangcharoen N, Bai H, Shah A H. A 3D cylindrical finite element model for thick curved beam stress analysis[J]. International journal for numerical methods in engineering, 2004, 59(4):511-531.

Richards T H, Daniels M J. Enhancing finite element surface stress predictions: A semi-analytic technique for axisymmetric solids[J]. The Journal of Strain Analysis for Engineering Design, 1987, 22(2):75-86.

Smart J. On the determination of boundary stresses in finite elements[J]. The Journal of Strain Analysis for Engineering Design, 1987, 22(2):87-96.

Sloboda A, Honarmandi P. Generalized elasticity method for curved beam stress analysis: analytical and numerical comparison for a lifting hook [J]. Mechanics based design of structures and machines,2007,35(3):319-332

Timoshenko S P, Goodier J N. Theory of Elasticity [M]. New York: McGraw- Hill Book Company, 1979.

Tutuncu N. Plane stress analysis of end loaded orthotropic curved beams of constant thickness with applications to full rings[J]. Journal of Mechanical Design, 1998,120(2):368-374.

Zhong W.X., Xu X.S., Zhang H.W. On a direct method for the problem of elastic curved beams[J]. Engineering Mechanics,1996,13(4):1-8.(In Chinese) 